\title{
Assessment of theoretical procedures for a diverse set of isomerization reactions involving double-bond migration in conjugated dienes
}

\author{
Li-Juan Yu and Amir Karton* \\ School of Chemistry and Biochemistry, The University of Western Australia, Perth, WA 6009, \\ Australia.
}

\begin{abstract}
A B S T R A C T
We introduce a representative database of 60 accurate diene isomerization energies obtained by means of the high-level, ab initio $\mathrm{W} n-\mathrm{F} 12$ thermochemical protocols. The isomerization reactions involve a migration of one double bond that breaks the $\pi$-conjugated system. The considered dienes involve a range of hydrocarbon functional groups, including linear, branched, and cyclic moieties. This set of benchmark isomerization energies allows an assessment of the performance of more approximate theoretical procedures for the calculation of $\pi$-conjugation stabilization energies in dienes. We evaluate the performance of a large number of density functional theory (DFT) and double-hybrid DFT (DHDFT) procedures. We find that, with few exceptions (most notably BMK-D3 and M05-2X), conventional DFT procedures have difficulty describing reactions of the type: conjugated diene $\rightarrow$ non-conjugated diene, with root mean square deviations (RMSDs) between 4.5-11.7 $\mathrm{kJ} \mathrm{mol}^{-1}$. However, DHDFT procedures show excellent performance with RMSDs well below the 'chemical accuracy' threshold.
\end{abstract}

Keywords: conjugated dienes $\bullet$ isomerization energies $\bullet$ density functional theory $\bullet$ double-hybrid $\mathrm{DFT} \cdot \mathrm{CCSD}(\mathrm{T}) \cdot$ composite methods $\bullet \mathrm{W} 2-\mathrm{F} 12$ theory

Corresponding Author. Tel.: +61 86488 3139. Fax: +61 86488 7330. E-mail address: amir.karton@uwa.edu.au (A. Karton). 


\section{Introduction}

Over the past two decades density functional theory (DFT) has become one of the most widely used electronic structure methods in materials and quantum chemistry due to its attractive accuracy-to-computational cost ratio relative to other electronic structure methods. With this increase in popularity there has been a proliferation in the number of developed DFT procedures. ${ }^{1}$ The approximations for the XC functional can be classified according to their rung on Perdew's 'Jacob's Ladder of DFT': (1) the local density approximation (LDA); (2) pure generalized gradient approximation (GGA) employing both the local density and the reduced density gradient; (3) the meta-GGAs (mGGA) which additionally employ the kinetic energy density; (4) the hybrid-meta-GGAs (hmGGA) which additionally involve the occupied orbitals; and (5) the double-hybrid $(\mathrm{DH})$ functionals which additionally employ the virtual orbitals. ${ }^{2,3}$ While, in general, the accuracy of DFT increases as one climbs the rungs of Jacob's Ladder at present no truly systematic path towards the exact solution exists. Thus, the only validation for a given DFT approximation is benchmarking against accurate reference data. Ideally, the benchmark data should: (i) have well-defined error bars that are much smaller (preferably, by an order of magnitude or more) than the intrinsic error of the method being evaluated, and (ii) be as large and chemically diverse as reasonably possible. ${ }^{4,5,6}$

It is well established that the performance of DFT (or for that matter of any approximate theoretical procedure) can vary for different types of reactions. In particular, the accuracy of a given approximate theoretical procedure should increase as larger molecular fragments are conserved on the two sides of the reaction, due to an increasing degree of error cancellation between reactants and products. For example, the performance of DFT improves along the sequence: atomization $\rightarrow$ isogyric $\rightarrow$ isodesmic $\rightarrow$ hypohomodesmotic $\rightarrow$ homodesmotic $\rightarrow$ hyperhomodesmotic reactions. ${ }^{7,8,9,10,11,12,13}$ In the context of hydrocarbon isomerization reactions, it has been shown that the performance of DFT for linear alkane $\rightarrow$ branched alkane isomerizations is significantly better than that for isogyric structural isomerizations. ${ }^{8,14,15,16,17,18,19,20}$ For example, the root mean square deviations (RMSDs) for a wide range of DFT methods for $\mathrm{C}_{8} \mathrm{H}_{8}$ isomer energy separations (which are mostly isogyric reactions in which the bonding situation is very different on both sides of the reaction) vary between 5.0$40 \mathrm{~kJ} \mathrm{~mol}^{-1} \cdot{ }^{15}$ On the other hand, the RMSDs for a wide range of dispersion-corrected DFT for linear $\rightarrow$ branched alkane isomerizations (i.e., reactions that conserve the number of $\mathrm{C}$ atoms in each hybridization state in addition to being isodesmic) are about one order of magnitude smaller, i.e., they vary between $0.5-4.0 \mathrm{~kJ} \mathrm{~mol}^{-1}$. $^{10}$ 
In the present work, we introduce a representative benchmark database of 60 diene isomerization energies (to be known as the DIE60 set). The reactions in the DIE60 database (Figure 1) are of the type conjugated diene $\rightarrow$ non-conjugated diene. The database covers a broad spectrum of structures, including linear and branched dienes $\left(\mathrm{C}_{n} \mathrm{H}_{2 n-2}\right)$ and cyclic dienes $\left(\mathrm{C}_{n} \mathrm{H}_{2 n-4}\right)$ $(n=5,6$, and 7). Reference isomerization energies at the $\operatorname{CCSD}(\mathrm{T}) / \mathrm{CBS}$ level (i.e., complete basis set limit $\operatorname{CCSD}(\mathrm{T})$ energies) are obtained by means of the high-level W2-F12 procedure (for the $\mathrm{C}_{5} \mathrm{H}_{6}, \mathrm{C}_{5} \mathrm{H}_{8}, \mathrm{C}_{6} \mathrm{H}_{8}, \mathrm{C}_{6} \mathrm{H}_{10}$, and $\mathrm{C}_{7} \mathrm{H}_{10}$ dienes) or with the W1-F12 procedure (for the $\mathrm{C}_{7} \mathrm{H}_{12}$ dienes). ${ }^{21}$ These benchmark values allow us to assess the performance of more approximate theoretical procedures for the isomerization energies. Specifically, we examine the performance of a variety of contemporary DFT procedures, including the recently developed double-hybrid DFT (DHDFT) methods, as well as a number of high-level composite thermochemistry procedures, and several conventional ab initio methods. We note that all the isomerization reactions in the DIE60 dataset are hypohomodesmotic, that is, in addition to being isodesmic (i.e., conserving numbers of each formal bond type), they also conserve the number of $\mathrm{C}$ atoms in each hybridization state and the hapticity (primary, secondary, and tertiary). The use of hypohomodesmotic transformations, in which the chemical environments (except for $\pi$ conjugation) are largely balanced on the two sides of the reaction, allows us to evaluate the performance of approximate theoretical procedures for the calculation of the $\pi$-conjugation stabilization energies. 


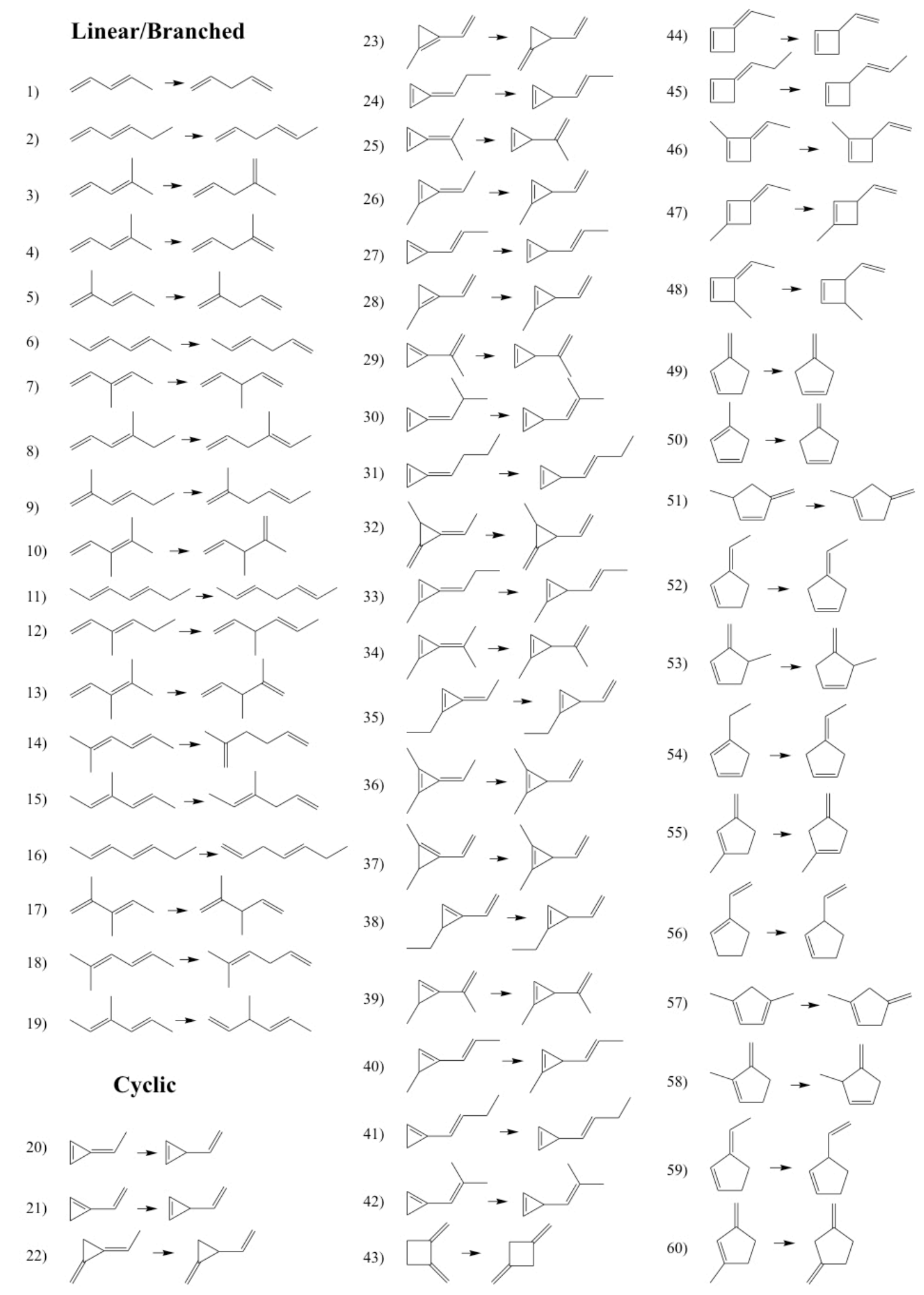

Figure 1. Isomerization reactions in the DIE60 database. 


\section{Computational Methods}

In order to obtain reliable reference isomerization energies for the DIE60 database, calculations have been carried out using the high-level, ab initio W2-F12 procedure with the Molpro 2012.1 program suite. ${ }^{22}$ W2-F12 theory ${ }^{21}$ (and its earlier versions W2 and W2.2 theories) ${ }^{23,24}$ represent layered extrapolations to the relativistic, all-electron $\operatorname{CCSD}(\mathrm{T}) / \mathrm{CBS}$ (coupled cluster with singles, doubles, and quasiperturbative triple excitations basis-set-limit energy). These composite theories include scalar-relativistic, diagonal Born-Oppenheimer, zeropoint vibrational energy, and enthalpic corrections and can achieve 'near-benchmark accuracy' for atomization reactions (e.g., W2-F12 theory is associated with a mean absolute deviation of $1.3 \mathrm{~kJ} \mathrm{~mol}^{-1}$ for a set of 140 very accurate atomization energies). ${ }^{5,10,21,23,24,25,26}$ Nevertheless, it should be pointed out that for the hypohomodesmotic isomerization reactions in the DIE60 database these theories should yield even better performance due to a large degree of systematic error cancelation between reactants and products. $5,7,8,9,10,27,28$

W2-F12 theory combines explicitly correlated F12 techniques ${ }^{29}$ with basis-set extrapolations in order to approximate the $\operatorname{CCSD}(\mathrm{T})$ basis-set-limit energy. Due to the drastically accelerated basis-set convergence of the F12 methods, ${ }^{30,31} \mathrm{~W} 2-\mathrm{F} 12$ is superior to the original W2 and W2.2 methods in terms of computational cost. ${ }^{21}$ For the sake of making the article selfcontained, we will briefly outline the various steps in W2-F12 theory (for further details see Ref. 21). The Hartree-Fock (HF) component is calculated with the VQZ-F12 basis set (where VQZF12 denotes the cc-pVQZ-F12 basis set of Peterson et al., ${ }^{30}$ which was specifically developed for explicitly correlated calculations). Note that the complementary auxiliary basis set (CABS) singles correction is included in the SCF energy. ${ }^{32,33,34}$ The valence CCSD-F12 correlation energy is extrapolated from the VTZ-F12 and VQZ-F12 basis sets, using the $E(L)=E_{\alpha}+\mathrm{A} / L^{\alpha}$ two-point extrapolation formula, with $\alpha=5$.94. Optimal values for the geminal Slater exponents $(\beta)$ used in conjunction with the VnZ-F12 basis sets were taken from Ref. 31. The quasiperturbative triples, (T), corrections are obtained from standard CCSD(T)/VTZ-F12 calculations (i.e., without inclusion of $\mathrm{F} 12$ terms) and scaled by the factor $f=0.987 \times \mathrm{E}^{\mathrm{MP} 2-\mathrm{F} 12} / \mathrm{E}^{\mathrm{MP} 2}$. This approach has been shown to accelerate the basis set convergence. ${ }^{21,35}$ In all of the explicitly correlated coupled cluster calculations the diagonal, fixed-amplitude 3 C(FIX) ansatz $z^{33,36,37,38}$ and the CCSD-F12b approximation are employed. ${ }^{34,35}$ The CCSD inner-shell contribution is calculated with the corevalence weighted correlation-consistent aug'-cc-pwCVTZ basis set of Peterson and Dunning, ${ }^{39}$ whilst the (T) inner-shell contribution is calculated with the cc-pwCVTZ(no f) basis set (where cc-pwCVTZ(no f) indicates the cc-pwCVTZ basis set without the $\mathrm{f}$ functions). The scalar relativistic contribution (in the second-order Douglas-Kroll-Hess approximation) ${ }^{40,41}$ is obtained 
as the difference between non-relativistic CCSD(T)/A'VTZ and relativistic CCSD(T)/A'VTZ-DK calculations. ${ }^{42}$ The diagonal Born-Oppenheimer corrections are calculated at the HF/cc-pVTZ level of theory using the CFOUR program suite. ${ }^{43}$

The isomerization energies for the larger $\mathrm{C}_{7} \mathrm{H}_{12}$ dienes have been obtained with the computationally more economical W1-F12 procedure. The computational protocol of the W1F12 method has been specified and rationalized in detail in Ref. 21 (see also discussion in Ref. 44). The main difference between $\mathrm{W} 1-\mathrm{F} 12$ and $\mathrm{W} 2-\mathrm{F} 12$ is that W1-F12 uses smaller basis sets for extrapolating the HF, CCSD-F12, and (T) contributions. Specifically, the HF and CCSD-F12 contributions are extrapolated from the VDZ-F12 and VTZ-F12 basis-sets using the two-point extrapolation formula with $\alpha=5.00$ and 3.38, respectively. The (T) valence correlation energy is obtained in the same way as in the original W1 theory, ${ }^{23}$ i.e., extrapolated from the $\mathrm{A}^{\prime} \mathrm{VDZ}$ and $\mathrm{A}^{\prime} \mathrm{VTZ}$ basis sets with $\alpha=3.22$ (where $\mathrm{A}^{\prime} \mathrm{VnZ}$ indicates the combination of the standard correlation-consistent cc-pVnZ basis sets on $\mathrm{H}^{45}$ and the aug-cc-pVnZ basis sets on $\left.\mathrm{C}\right) .{ }^{46}$

The geometries of all structures have been obtained at the B3LYP-D3/cc-pVTZ level of theory. ${ }^{47,48,49,50}$ Empirical D3 dispersion corrections ${ }^{5152}$ are included using the Becke-Johnson ${ }^{53}$ damping potential as recommended in Ref. 50 (denoted by the suffix -D3). We note that the suffix -D in B97-D and $\omega$ B97X-D indicates the original dispersion correction rather than the D3 correction. Harmonic vibrational analyses have been performed to confirm each stationary point as an equilibrium structure (i.e., all real frequencies). Zero-point vibrational energy and enthalpic corrections have been obtained from such calculations. All geometry optimizations and frequency calculations were performed using the Gaussian 09 program suite. ${ }^{54}$

The DFT exchange-correlation functionals considered in the present study (ordered by their rung on Jacob's Ladder) ${ }^{55}$ are the pure generalized gradient approximation (GGA) functionals: BLYP,${ }^{47,56}$ B97-D $,{ }^{57} \mathrm{HCTH} 407,{ }^{58} \mathrm{PBE},{ }^{59} \mathrm{BP} 86,{ }^{56,60} \mathrm{BPW} 91 ;{ }^{56,61}$ SOGGA11, ${ }^{62} \mathrm{~N} 12 ;{ }^{63}$ the metaGGAs (MGGAs): M06-L, ${ }^{64}$ TPSS, ${ }^{65} \tau$-HCTH, ${ }^{66} \mathrm{VSXC}^{67}{ }^{67} \mathrm{BB} 95,{ }^{68} \mathrm{M} 11-\mathrm{L},{ }^{69} \mathrm{MN} 12-\mathrm{L} ;{ }^{70}$ the hybrid-GGAs (HGGAs): BH\&HLYP, ${ }^{71}$ B3LYP,,${ }^{47,49}$ B3P86, ${ }^{48,60} \mathrm{~B} 3 \mathrm{PW} 91,{ }^{48,} 61$ PBE0, ${ }^{72} \mathrm{~B} 97-$ $1,{ }^{73} \mathrm{~B} 98,{ }^{74} \mathrm{X} 3 \mathrm{LYP},{ }^{75}$ SOGGA11-X; ${ }^{76}$ the hybrid-meta-GGAs (HMGGAs): M05, ${ }^{77} \mathrm{M} 05-2 \mathrm{X},{ }^{78}$ M06, ${ }^{79} \mathrm{M} 06-2 \mathrm{X},{ }^{79} \mathrm{M} 06-\mathrm{HF},{ }^{79} \mathrm{BMK},{ }^{80} \mathrm{~B} 1 \mathrm{~B} 95,{ }^{56,68} \mathrm{TPSSh}^{81} \tau$-HCTHh, ${ }^{66} \mathrm{PW} 6 \mathrm{~B} 95,{ }^{82}$ and the DHDFT procedures: B2-PLYP,${ }^{83}$ B2GP-PLYP,${ }^{84}$ B2K-PLYP,${ }^{85}$ B2T-PLYP, ${ }^{85}$ DSD-BLYP ${ }^{86}$ DSD-PBEP86, ${ }^{87,88}$ PWPB95. ${ }^{4}$ We also consider the following range-separated (RS) functionals: CAM-B3LYP,${ }^{89}$ LC- $\omega$ PBE $,{ }^{90} \omega \mathrm{B} 97,{ }^{91} \omega \mathrm{B} 97 \mathrm{X},{ }^{91} \omega \mathrm{B} 97 \mathrm{X}-\mathrm{D},{ }^{92}$ and M11. ${ }^{93}$

In addition, the performance of composite thermochemical procedures and standard $\mathrm{ab}$ initio methods is also assessed. We consider the following composite procedures: G4, ${ }^{94}$ 
G4(MP2), ${ }^{95}$ G4(MP2)-6X, ${ }^{96}$ CBS-QB3, ${ }^{97}$ and CBS-APNO, ${ }^{98}$ and the following ab initio methods: MP2, SCS-MP2 $,{ }^{99} \mathrm{MP} 2.5,{ }^{100} \mathrm{MP} 3, \mathrm{SCS}-\mathrm{MP} 3,{ }^{101} \mathrm{MP} 4, \mathrm{CCSD}, \mathrm{SCS}-\mathrm{CCSD},{ }^{102} \mathrm{SCS}(\mathrm{MI}) \mathrm{CCSD},{ }^{103}$ and $\operatorname{CCSD}(\mathrm{T})$. The performance of the DFT and standard ab initio procedures is investigated in conjunction with the cc-pVnZ $(n=\mathrm{D}, \mathrm{T}, \mathrm{Q})$ correlation-consistent basis sets of Dunning. ${ }^{45}$

\section{Results and Discussion}

3.1. Benchmark isomerization energies for the DIE60 dataset. The DIE60 database is comprised of 60 prototypical isomerization reactions (shown in Fig. 1) of the type:

$$
\text { Conjugated diene } \rightarrow \text { Non-conjugated diene }
$$

All the reactions involve a migration of one double bond, which breaks the conjugated $\pi$-system. The DIE60 database covers a broad spectrum of structures, including linear/branched dienes $\left(\mathrm{C}_{n} \mathrm{H}_{2 n-2}\right)$ and cyclic dienes $\left(\mathrm{C}_{n} \mathrm{H}_{2 n-4}\right)(n=5,6$, and 7). Benchmark reference data have been obtained by means of the high-level W2-F12 procedure (for the $\mathrm{C}_{5} \mathrm{H}_{6}, \mathrm{C}_{5} \mathrm{H}_{8}, \mathrm{C}_{6} \mathrm{H}_{8}, \mathrm{C}_{6} \mathrm{H}_{10}$, and $\mathrm{C}_{7} \mathrm{H}_{10}$ dienes) and with the W1-F12 procedure (for the $\mathrm{C}_{7} \mathrm{H}_{12}$ dienes). ${ }^{21} \mathrm{~W} 2-\mathrm{F} 12$ and W1-F12 theories represent layered extrapolation to the relativistic, all-electron $\operatorname{CCSD}(\mathrm{T})$ basis-set limit, and can achieve an accuracy in the $\mathrm{kJ} \mathrm{mol}^{-1}$ range for molecules whose wave functions are dominated by dynamical correlation. We note that for the 48 reactions for which we have both W2-F12 and W1-F12 reaction energies, W1-F12 attains an RMSD of $0.15 \mathrm{~kJ} \mathrm{~mol}^{-1}$ relative to the W2-F12 values, with the largest deviation (in absolute value) being $0.3 \mathrm{~kJ} \mathrm{~mol}^{-1}$ (Table S1, Supplementary data).

Since W2-F12 and W1-F12 represent layered extrapolations to the all-electron CCSD(T) basis-set-limit energy, it is of interest to estimate whether the contributions from post-CCSD(T) excitations are likely to be significant. The percentage of the total atomization energy accounted for by parenthetical connected triple excitations, \% $\left.\mathrm{TAE}_{e}[\mathrm{~T})\right]$, has been shown to be a reliable energy-based diagnostic for the importance of nondynamical correlation effects. It has been suggested that $\% \mathrm{TAE}_{e}[(\mathrm{~T})]<2 \%$ indicates systems that are dominated by dynamical correlation. ${ }^{24}$ Table S2 (Supplementary data) gathers the \% $\left.\mathrm{TAE}_{e}[\mathrm{~T})\right]$ values for the reactants and products involved in the DIE60 dataset. The $\% \mathrm{TAE}_{e}[(\mathrm{~T})]$ values for these species lie in the range $1.44-1.88 \%$. These values suggest that all the species in the DIE60 database are dominated by dynamical correlation effects, and that our bottom-of-the-well CCSD(T)/CBS benchmark isomerization energies should be within $2-3 \mathrm{~kJ} \mathrm{~mol}^{-1}$ from the reaction energies at the full configuration interaction (FCI) basis-set limit. ${ }^{5,21}$ 
The component breakdown of the W2-F12 and W1-F12 reaction energies are gathered in Table 1. For the reactants and products involved in reactions 1, 2, and $\mathbf{6}$ experimental heats of formation at $298 \mathrm{~K}$ are available from the NIST thermochemical database (Table S3, Supplementary data). ${ }^{104}$ These result in reaction enthalpies at $298 \mathrm{~K}\left(\Delta H_{298}\right)$ of $30.5 \pm 1.5(\mathbf{1})$, $20.0 \pm 2.8(2)$ and $30.0 \pm 2.8(6) \mathrm{kJ} \mathrm{mol}^{-1}$. Our W2-F12 reaction enthalpies are in excellent agreement with the experimental values. Specifically, the following deviations (theoryexperiment) are obtained: $-1.0(\mathbf{1}),-2.3(\mathbf{2})$, and $0.0(\mathbf{6}) \mathrm{kJ} \mathrm{mol}^{-1}$. Note that these deviations are within the experimental error bars.

Table 1. Component breakdown of the benchmark $\mathrm{W} n-\mathrm{F} 12$ reaction energies for the isomerization reactions in the DIE60 database (shown in Fig. 1) ${ }^{a}$

\begin{tabular}{ccccccccccc}
\hline Reaction & $\Delta$ SCF & $\Delta$ CCSD & $\Delta(\mathrm{T})$ & $\Delta \mathrm{CV}^{b}$ & $\Delta$ Rel. $^{c}$ & $\Delta \mathrm{ZPVE}^{d}$ & $\Delta E_{e}{ }^{e}$ & $\Delta H_{0}{ }^{f, g}$ & $H_{298}-H_{0}{ }^{h}$ & $\Delta H_{298}{ }^{f, g}$ \\
\hline 1 & 27.5 & 0.0 & 1.7 & 0.2 & 0.0 & 0.3 & 29.4 & 29.7 & -0.2 & $29.5^{i}$ \\
2 & 17.3 & -0.2 & 1.7 & -0.1 & 0.0 & -1.4 & 18.7 & 17.3 & 0.4 & $17.7^{i}$ \\
3 & 18.4 & 1.4 & 2.0 & 0.2 & 0.0 & 0.6 & 22.0 & 22.6 & -0.5 & 22.1 \\
4 & 21.8 & 1.3 & 2.1 & 0.2 & 0.0 & 0.5 & 25.4 & 25.9 & -0.4 & 25.5 \\
5 & 26.1 & 0.5 & 1.7 & 0.2 & 0.0 & -0.1 & 28.5 & 28.4 & 0.0 & 28.5 \\
6 & 27.6 & 0.2 & 1.8 & 0.2 & 0.0 & 0.5 & 29.8 & 30.3 & -0.3 & $30.0^{i}$ \\
7 & 25.7 & 2.6 & 2.1 & 0.4 & 0.0 & 0.7 & 30.8 & 31.5 & -0.7 & 30.9 \\
8 & 14.2 & -0.2 & 1.7 & 0.0 & 0.0 & -1.3 & 15.6 & 14.3 & 0.4 & 14.6 \\
9 & 15.9 & 0.2 & 1.6 & -0.1 & 0.0 & -1.7 & 17.7 & 16.0 & 0.5 & 16.5 \\
10 & 7.3 & 6.0 & 2.9 & 0.2 & -0.1 & 1.1 & 16.5 & 17.5 & -1.4 & 16.1 \\
11 & 17.8 & -0.2 & 1.7 & 0.0 & 0.0 & -1.2 & 19.3 & 18.1 & 0.3 & 18.4 \\
12 & 15.6 & 2.5 & 2.1 & 0.1 & 0.0 & -1.2 & 20.3 & 19.0 & 0.0 & 19.1 \\
13 & 11.0 & 5.7 & 3.0 & 0.3 & -0.1 & 1.0 & 20.0 & 20.9 & -1.4 & 19.5 \\
14 & 19.9 & 0.9 & 2.1 & 0.2 & 0.0 & 0.5 & 23.1 & 23.6 & -0.6 & 22.9 \\
15 & 22.7 & 0.5 & 1.7 & 0.2 & 0.0 & 0.0 & 25.1 & 25.1 & -0.1 & 25.1 \\
16 & 25.1 & 0.4 & 1.8 & 0.2 & 0.0 & 0.7 & 27.5 & 28.2 & -0.3 & 27.9 \\
17 & 26.1 & 1.4 & 1.9 & 0.2 & 0.0 & 0.0 & 29.7 & 29.7 & -0.4 & 29.2 \\
18 & 29.6 & -1.0 & 1.6 & 0.2 & 0.0 & 0.6 & 30.4 & 31.0 & -0.2 & 30.7 \\
19 & 25.3 & 2.7 & 2.1 & 0.4 & -0.1 & 0.9 & 30.6 & 31.4 & -0.8 & 30.7 \\
20 & -6.2 & -7.3 & -0.8 & 0.4 & -0.1 & 0.9 & -13.9 & -13.1 & -0.7 & -13.8 \\
21 & 18.2 & -1.0 & 1.2 & 0.2 & 0.0 & -2.0 & 18.6 & 16.6 & 0.0 & 16.5 \\
22 & -27.8 & 1.1 & 1.9 & 0.0 & 0.0 & 0.7 & -24.7 & -24.1 & -1.4 & -25.4 \\
23 & -30.7 & 2.8 & 2.0 & 0.2 & 0.0 & 1.8 & -25.7 & -23.9 & -0.9 & -24.8 \\
24 & -14.5 & -7.6 & -0.8 & 0.1 & -0.1 & -0.8 & -22.8 & -23.6 & 0.0 & -23.6 \\
25 & -10.5 & -8.7 & -1.0 & 0.4 & -0.1 & 1.7 & -19.9 & -18.2 & -1.2 & -19.4 \\
26 & -1.8 & -8.2 & -0.9 & 0.4 & -0.1 & 0.9 & -10.5 & -9.7 & -0.8 & -10.5 \\
27 & 12.6 & -1.3 & 1.1 & 0.2 & 0.0 & -1.4 & 12.6 & 11.1 & -0.5 & 10.6 \\
28 & 16.2 & -0.7 & 1.2 & 0.2 & 0.0 & -1.8 & 16.8 & 15.0 & -0.1 & 14.9 \\
29 & 22.9 & -4.8 & 0.5 & 0.2 & 0.0 & -1.5 & 18.7 & 17.2 & -0.5 & 16.8
\end{tabular}




\begin{tabular}{ccccccccccc}
30 & -13.8 & -9.8 & -1.3 & 0.0 & 0.0 & -0.6 & -24.9 & -25.5 & 0.4 & -25.2 \\
31 & -16.7 & -4.1 & -0.4 & 0.2 & -0.1 & -0.6 & -21.0 & -21.7 & 0.1 & -21.6 \\
32 & -25.0 & 0.8 & 1.7 & 0.2 & 0.0 & 2.0 & -22.3 & -20.3 & -1.0 & -21.3 \\
33 & -9.5 & -8.5 & -0.9 & 0.1 & 0.0 & -0.7 & -18.8 & -19.6 & -0.1 & -19.8 \\
34 & -7.0 & -9.6 & -1.1 & 0.4 & -0.1 & 1.7 & -17.3 & -15.7 & -1.2 & -16.9 \\
35 & -1.7 & -8.2 & -0.9 & 0.4 & -0.1 & 0.9 & -10.4 & -9.5 & -0.9 & -10.4 \\
36 & 1.5 & -8.6 & -1.0 & 0.4 & -0.1 & 0.7 & -7.7 & -7.1 & -0.8 & -7.8 \\
37 & -1.9 & 3.0 & 1.7 & -0.1 & 0.0 & -0.8 & 2.7 & 1.9 & 0.3 & 2.2 \\
38 & -2.7 & 3.8 & 1.8 & -0.1 & 0.0 & -0.8 & 2.8 & 2.0 & 0.3 & 2.3 \\
39 & 3.3 & -1.4 & 0.9 & -0.1 & 0.0 & -0.5 & 2.7 & 2.2 & -0.1 & 2.1 \\
40 & 3.3 & 2.1 & 1.7 & 0.0 & 0.0 & -0.9 & 7.0 & 6.1 & 0.4 & 6.4 \\
41 & 23.0 & -2.0 & 1.1 & 0.2 & 0.0 & -2.0 & 22.4 & 20.4 & 0.0 & 20.3 \\
42 & 26.1 & -1.6 & 1.3 & 0.3 & 0.0 & -1.9 & 26.1 & 24.1 & 0.2 & 24.2 \\
43 & 8.1 & 2.0 & 2.1 & -0.1 & 0.0 & -1.6 & 12.1 & 10.5 & 0.1 & 10.6 \\
44 & 13.9 & -0.1 & 1.5 & 0.2 & 0.0 & 0.8 & 15.6 & 16.4 & -0.6 & 15.7 \\
45 & 3.8 & -0.2 & 1.5 & 0.0 & 0.0 & -1.0 & 5.1 & 4.1 & 0.0 & 4.1 \\
46 & 14.9 & -0.8 & 1.2 & 0.2 & 0.0 & 0.8 & 15.5 & 16.3 & -0.7 & 15.6 \\
47 & 14.8 & -0.5 & 1.4 & 0.3 & 0.0 & 0.9 & 16.0 & 16.9 & -0.7 & 16.2 \\
48 & 19.3 & -2.4 & 1.1 & 0.2 & 0.0 & 1.0 & 18.3 & 19.2 & -0.8 & 18.5 \\
49 & 16.1 & -0.4 & 1.8 & -0.1 & 0.0 & -1.2 & 17.5 & 16.3 & -0.1 & 16.2 \\
50 & 18.0 & 6.4 & 3.2 & 0.3 & 0.0 & 1.1 & 28.0 & 29.1 & -0.4 & 28.7 \\
51 & 3.3 & 1.6 & 2.2 & -0.3 & 0.0 & -2.3 & 6.8 & 4.6 & 0.6 & 5.2 \\
52 & 15.8 & -0.2 & 1.9 & 0.0 & 0.0 & -1.2 & 17.5 & 16.3 & -0.1 & 16.2 \\
53 & 15.4 & 0.8 & 2.0 & 0.0 & 0.0 & -1.4 & 18.1 & 16.7 & 0.3 & 17.0 \\
54 & 9.5 & 5.1 & 3.1 & 0.0 & 0.0 & -0.7 & 17.7 & 17.1 & 0.4 & 17.5 \\
55 & 17.8 & -0.6 & 1.9 & 0.0 & 0.0 & -1.1 & 19.0 & 17.9 & -0.1 & 17.7 \\
56 & 22.0 & 0.7 & 1.5 & 0.2 & 0.0 & -0.8 & 24.5 & 23.6 & 0.1 & 23.7 \\
57 & 14.3 & 6.3 & 3.2 & 0.3 & 0.0 & 1.2 & 24.1 & 25.2 & -0.6 & 24.6 \\
58 & 28.8 & -1.3 & 1.4 & 0.2 & 0.0 & -0.4 & 29.0 & 28.6 & -0.6 & 28.1 \\
59 & 27.7 & 0.8 & 1.7 & 0.5 & -0.1 & 1.5 & 30.7 & 32.1 & -1.1 & 31.1 \\
60 & 35.6 & -1.6 & 1.9 & 0.2 & 0.0 & 0.4 & 36.0 & 36.4 & -1.0 & 35.4 \\
\hline
\end{tabular}

${ }^{a}$ Reference values are obtained at the $\mathrm{W} 1-\mathrm{F} 12$ level for the reactions involving the $\mathrm{C}_{7} \mathrm{H}_{12}$, and at the $\mathrm{W} 2-\mathrm{F} 12$ level for all the rest of the reactions. ${ }^{b}$ Core-valence correction. ${ }^{c}$ Scalar-relativistic correction. ${ }^{d}$ Zero-point vibrational energy correction from B3LYP-D3/cc-pVTZ harmonic calculations (scaled by 0.99 ). ${ }^{e}$ Nonrelativistic, all-electron, vibrationless, $\mathrm{DBOC}$-exclusive $\operatorname{CCSD}(\mathrm{T})$ basis set limit reference isomerization energies (these are used for the evaluation of the DFT, composite, and ab initio procedures). ${ }^{f}$ Relativistic, all-electron, ZPVE-inclusive, DBOCinclusive $\operatorname{CCSD}(\mathrm{T})$ basis set limit reference isomerization energies at 0 and $298 \mathrm{~K}$ (for comparison with experiment). ${ }^{g}$ The DBOC contribution to the reactions is generally below $0.05 \mathrm{~kJ} \mathrm{~mol}^{-1}$ (Table S4, Supplementary data). ${ }^{h}$ Enthalpy functions $\left(H_{298}-H_{0}\right)$ are obtained within the rigid rotor-harmonic oscillator approximation from the B3LYP-D3/ccpVTZ calculated geometry and harmonic frequencies. ${ }^{i}$ The experimental $\left(\Delta H_{298}\right)$ values are $30.5(\mathbf{1}), 20.0(\mathbf{2})$, and $30.0(6) \mathrm{kJ} \mathrm{mol}^{-1}$ (taken from Ref. 104, see also Table S3, Supplementary data). 
3.2. Overview of the isomerization reactions in the DIE60 dataset. The reactions in the DIE60 database (see Fig. 1 and Eq. 1) may be divided into two subsets, reactions involving linear/branched structures (1-19):

$$
\text { Linear/branched conjugated diene } \rightarrow \text { Linear/branched non-conjugated diene }
$$

and reactions involving cyclic structures $(\mathbf{2 0 - 6 0})$ :

$$
\text { Cyclic conjugated diene } \rightarrow \text { Cyclic non-conjugated diene }
$$

The reactions of type (1a) are all endothermic, the reaction enthalpies $\left(\Delta H_{298}\right)$ vary between 14.6 (8) and 30.9 (7) kJ mol ${ }^{-1}$. The endothermicity of the reactions may, in part, be attributed to the breaking the conjugated $\pi$-system, and to hyperconjugation effects of the sigma bonds surrounding the migrating double bond. The reaction energies of reactions (1b) span a much wider range, from $-25.4(\mathbf{2 2})$ to $+35.4(\mathbf{6 0}) \mathrm{kJ} \mathrm{mol}^{-1}$. Figure 2 depicts the exothermic reactions, with $\Delta H_{298}$ values varying between -25.4 and $-7.8 \mathrm{~kJ} \mathrm{~mol}^{-1}$ (Table 1). All these reactions involve cyclic 3-membered rings in which the number of $\mathrm{sp}^{2}$ carbons in the ring is not balanced on the two sides of the reaction. In particular, the reactants have $n+1 \mathrm{sp}^{2}$ carbons in the ring, whilst the products have only $n \mathrm{sp}^{2}$ carbons in the ring $(n=1,2)$. The exothermicity of these reactions is, in part, attributed to the reduced strain energy in the products relative to the reactants. Or in other words, the decrease in the strain energy when moving from a ring with $n+1 \mathrm{sp}^{2}$ carbons to $n \mathrm{sp}^{2}$ carbons is larger than the $\pi$-conjugation stabilization energy involved in the reactants.
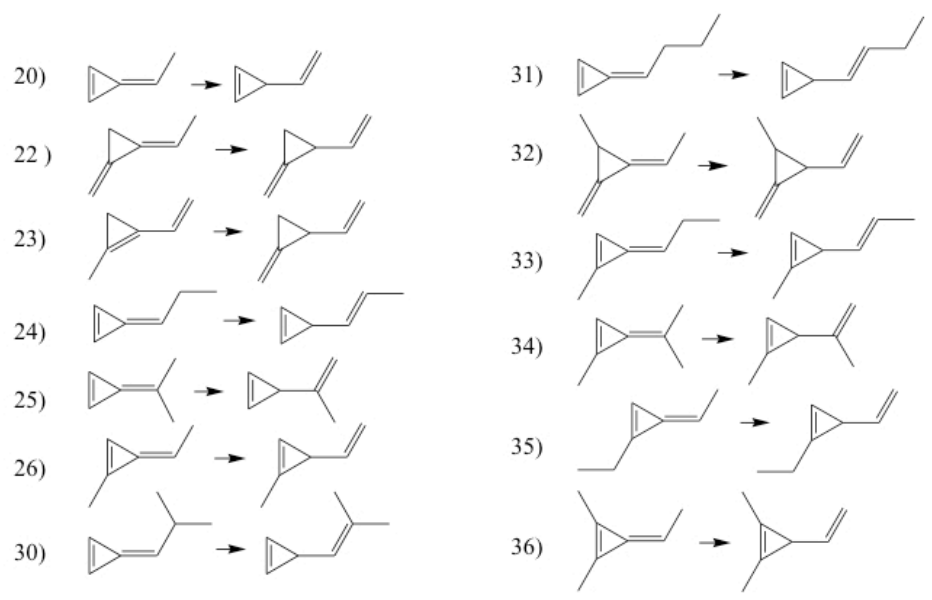

Figure 2. Reactions in the DIE60 database involving 3-membered rings in which the number of $\mathrm{sp}^{2}$ carbons in the ring is not balanced on the two sides of the reaction. In all cases the reactant has $n+1 \mathrm{sp}^{2}$ carbons in the ring and the product has $n \mathrm{sp}^{2}$ carbons in the ring $(n=1,2)$. 


\subsection{Performance of DFT procedures for the isomerization reactions in the DIE60 database.}

The W2-F12 and W1-F12 reaction energies provide a benchmark set of values that allows the evaluation of the performance of computationally less demanding procedures for the calculation of $\pi$-conjugation stabilization energies in linear, branched, and cyclic dienes. For a rigorous comparison with the DFT data, secondary effects that are not explicitly included in the DFT calculations, such as relativity and zero-point vibrational corrections, are excluded from the $\mathrm{Wn}-$ F12 reference values.

3.3.1. Entire DIE60 dataset. Table 2 gives the root mean square deviation (RMSD), mean absolute deviation (MAD), and mean signed deviation (MSD) from our benchmark Wn-F12 results for a series of contemporary DFT functionals (with and without empirical D3 dispersion corrections). We start by making the following general observations:

$>$ With few exceptions, the GGA, MGGA, HGGA, and HMGGA functionals attain RMSDs above the threshold of 'chemical accuracy' (namely, RMSDs $=4.5-11.7 \mathrm{~kJ} \mathrm{~mol}^{-1}$ ). The exceptions are (RMSDs are given in parenthesis): BMK-D3 (1.6), BMK (2.1), M05-2X (2.5), M06-2X (3.5), and BH\&HLYP-D3 (3.8 kJ mol$\left.{ }^{-1}\right)$.

$>$ All of the range-separated functionals give reasonably good performance with RMSDs approaching or below the threshold of 'chemical accuracy' (specifically, the RMSDs vary

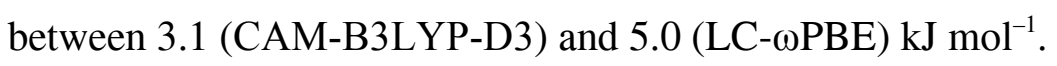

$>$ The double-hybrid procedures give excellent performance. The best performing functionals attain RMSDs of 1.4 (DSD-BLYP) and 1.6 (B2GP-PLYP) kJ mol${ }^{-1}$.

$>$ All the GGA, MGGA, HGGA, and HMGGA functionals tend to systematically overestimate the reactions energies, as evident from MSD $\approx$ MAD (with the notable exception of M06-HF). However, most of the range-separated and double-hybrid functionals give the desirable near-zero MSDs (generally, between $0.0-0.5 \mathrm{~kJ} \mathrm{~mol}^{-1}$, in absolute value).

Dispersion corrections systematically improve the agreement with the Wn-F12 results. The RMSDs are reduced by $\sim 10-20 \%$ upon inclusion of the D3 dispersion corrections. 
Table 2. Statistical analysis for the performance of DFT procedures for the calculation of the diene isomerization energies in the DIE60 database (in $\left.\mathrm{kJ} \mathrm{mol}^{-1}\right)^{a, b}$

\begin{tabular}{|c|c|c|c|c|c|}
\hline Type $^{c}$ & Method & RMSD & MAD & MSD & $\mathrm{LD}^{d}$ \\
\hline \multirow[t]{11}{*}{$\overline{\mathrm{GGA}}$} & BLYP & 8.3 & 7.6 & 7.6 & $15.7(24)$ \\
\hline & BLYP-D3 & 6.6 & 6.2 & 6.2 & $13.0(5)$ \\
\hline & B97-D & 7.7 & 7.3 & 7.3 & $13.6(5)$ \\
\hline & НСТН407 & 11.3 & 10.2 & 10.1 & $22.6(\mathbf{2 6})$ \\
\hline & PBE & 9.4 & 8.6 & 8.6 & $16.4(5)$ \\
\hline & PBE-D3 & 8.6 & 8.0 & 8.0 & $15.5(5)$ \\
\hline & BP86 & 9.1 & 8.3 & 8.3 & $16.2(5)$ \\
\hline & BP86-D3 & 7.5 & 7.1 & 7.1 & $14.0(5)$ \\
\hline & BPW91 & 9.7 & 8.8 & 8.8 & $17.4(5)$ \\
\hline & SOGGA11 & 9.3 & 8.3 & 8.3 & $20.6(\mathbf{2 4})$ \\
\hline & N12 & 9.6 & 8.8 & 8.8 & $15.9(5)$ \\
\hline \multirow[t]{8}{*}{ MGGA } & M06-L & 11.7 & 10.5 & 10.4 & $18.4(47)$ \\
\hline & TPSS & 9.3 & 8.6 & 8.6 & $15.7(5)$ \\
\hline & TPSS-D3 & 8.2 & 7.8 & 7.8 & $14.3(5)$ \\
\hline & $\tau$-HCTH & 10.8 & 9.8 & 9.8 & $20.0(\mathbf{2 6})$ \\
\hline & VSXC & 9.9 & 8.8 & 7.2 & $19.7(60)$ \\
\hline & BB95 & 9.6 & 8.7 & 8.7 & $17.6(5)$ \\
\hline & M11-L & 9.9 & 8.9 & 8.8 & $16.0(5)$ \\
\hline & MN12-L & 10.5 & 9.5 & 9.3 & $17.1(\mathbf{6 0})$ \\
\hline \multirow[t]{13}{*}{ HGGA } & BH\&HLYP & 4.5 & 3.8 & 3.4 & $10.4(26)$ \\
\hline & BH\&HLYP-D3 & 3.8 & 3.1 & 2.7 & $8.0(36)$ \\
\hline & B3LYP & 6.6 & 6.0 & 5.9 & $12.0(\mathbf{2 6})$ \\
\hline & B3LYP-D3 & 5.3 & 4.9 & 4.8 & $9.3(\mathbf{2 6})$ \\
\hline & B3P86 & 7.6 & 6.8 & 6.7 & $12.8(\mathbf{2 6})$ \\
\hline & B3PW91 & 7.9 & 7.0 & 6.9 & $14.5(\mathbf{2 6})$ \\
\hline & B3PW91-D3 & 6.4 & 5.7 & 5.7 & $11.5(\mathbf{2 6})$ \\
\hline & PBE0 & 7.3 & 6.5 & 6.4 & $13.6(26)$ \\
\hline & PBE0-D3 & 6.5 & 5.8 & 5.8 & $12.1(26)$ \\
\hline & B97-1 & 5.8 & 5.2 & 5.2 & $9.9(5)$ \\
\hline & B98 & 5.7 & 5.1 & 5.0 & $9.6(5)$ \\
\hline & X3LYP & 6.3 & 5.7 & 5.7 & $11.4(\mathbf{2 6})$ \\
\hline & SOGGA11-X & 5.6 & 4.7 & 4.6 & $11.9(26)$ \\
\hline \multirow[t]{13}{*}{ HMGGA } & M05 & 7.7 & 6.4 & 6.1 & $17.5(26)$ \\
\hline & M05-2X & 2.5 & 1.7 & 1.2 & $6.0(1)$ \\
\hline & M06 & 6.6 & 5.6 & 5.3 & $13.2(\mathbf{1})$ \\
\hline & M06-2X & 3.5 & 2.5 & 1.9 & $8.7(1)$ \\
\hline & M06-HF & 6.0 & 5.2 & -4.5 & $7.5(22)$ \\
\hline & $\mathrm{BMK}$ & 2.1 & 1.8 & 1.4 & $4.1(5)$ \\
\hline & BMK-D3 & 1.6 & 1.3 & 0.2 & $2.5(52)$ \\
\hline & B1B95 & 7.2 & 6.4 & 6.3 & $12.9(\mathbf{2 6})$ \\
\hline & B1B95-D3 & 6.5 & 5.7 & 5.7 & $11.8(\mathbf{3 5})$ \\
\hline & TPSSh & 8.4 & 7.7 & 7.7 & $14.0(26)$ \\
\hline & $\tau$-HCTHh & 6.7 & 6.1 & 6.0 & $11.6(5)$ \\
\hline & PW6B95 & 6.6 & 5.9 & 5.8 & $11.3(\mathbf{3 4})$ \\
\hline & PW6B95-D3 & 6.3 & 5.6 & 5.6 & $10.6(27)$ \\
\hline
\end{tabular}




\begin{tabular}{|c|c|c|c|c|c|}
\hline \multirow[t]{8}{*}{$\mathrm{RS}$} & CAM-B3LYP & 3.8 & 3.0 & 2.5 & $9.4(26)$ \\
\hline & CAM-B3LYP-D3 & 3.1 & 2.3 & 1.8 & $7.6(25)$ \\
\hline & $\mathrm{LC}-\omega \mathrm{PBE}$ & 5.0 & 3.5 & 0.9 & $12.2(27)$ \\
\hline & LC- $\omega$ PBE-D3 & 4.8 & 3.6 & 0.1 & $11.2(\mathbf{1})$ \\
\hline & $\omega \mathrm{B} 97$ & 4.2 & 3.2 & -0.2 & $9.9(\mathbf{1})$ \\
\hline & $\omega B 97 X$ & 3.6 & 2.5 & 0.6 & $8.8(\mathbf{1})$ \\
\hline & $\omega B 97 X-D$ & 3.4 & 2.4 & 1.8 & $8.2(1)$ \\
\hline & M11 & 3.9 & 2.9 & 0.6 & $9.6(27)$ \\
\hline \multirow[t]{11}{*}{$\mathrm{DH}$} & B2-PLYP & 4.2 & 3.9 & 3.9 & $7.0(26)$ \\
\hline & B2-PLYP-D3 & 3.4 & 3.3 & 3.3 & $5.5(25)$ \\
\hline & B2GP-PLYP & 1.6 & 1.2 & -0.3 & $3.8(\mathbf{1 0})$ \\
\hline & B2GP-PLYP-D3 & 1.6 & 1.3 & -0.6 & $4.2(\mathbf{1 0})$ \\
\hline & B2K-PLYP & 11.0 & 8.8 & 5.5 & $31.3(\mathbf{5 1})$ \\
\hline & B2T-PLYP & 1.9 & 1.5 & -0.6 & $4.2(\mathbf{2 4})$ \\
\hline & DSD-BLYP & 1.4 & 1.1 & -0.1 & $3.2(24)$ \\
\hline & DSD-PBEP86 & 2.7 & 2.5 & 2.5 & $5.0(26)$ \\
\hline & DSD-PBEP86-D3 & 2.1 & 1.9 & 1.9 & $4.9(31)$ \\
\hline & PWPB95 & 4.0 & 3.5 & 3.4 & 7.4 (35) \\
\hline & PWPB95-D3 & 3.8 & 3.3 & 3.3 & $7.1(27)$ \\
\hline
\end{tabular}

${ }^{a}$ The standard DFT calculations were carried out in conjunction with the cc-pVTZ basis set, while the DHDFT calculations, which exhibit slower basis set convergence, were carried out in conjunction with the cc-pVQZ basis set. ${ }^{b} \mathrm{RMSD}=$ root mean square deviation, $\mathrm{MAD}=$ mean absolute deviation, $\mathrm{MSD}=$ mean signed deviation, $\mathrm{LD}=$ largest deviation (in absolute value). ${ }^{c} \mathrm{GGA}=$ generalized gradient approximation, $\mathrm{HGGA}=$ hybrid-GGA, MGGA = metaGGA, RS = range-separated HGGA, HMGGA = hybrid-meta-GGA, DH $=$ double hybrid. ${ }^{d}$ The reaction numbers are given in parenthesis (see Fig. 1).

The eleven considered GGA functionals show relatively poor performance with RMSDs = 6.6-11.3 $\mathrm{kJ} \mathrm{mol}^{-1}$, where all the GGA functionals without a dispersion correction give RMSDs above $8 \mathrm{~kJ} \mathrm{~mol}^{-1}$. Of the dispersion-corrected GGAs, the functionals that gives RMSDs below 8 $\mathrm{kJ} \mathrm{mol}^{-1}$ are: BLYP-D3 (6.6), BP86-D3 (7.5), and B97-D (7.7 $\mathrm{kJ} \mathrm{mol}^{-1}$ ). Inclusion of the kinetic energy density in the MGGA procedures does not improve the performance. In fact, none of the considered MGGA functionals (with or without the dispersion correction) attains an RMSD below $8 \mathrm{~kJ} \mathrm{~mol}^{-1}$. We note that reaction 5 seems to be particularly problematic for most of the GGA and MGGA procedures. For example, for 12 of the 19 considered functionals the largest deviation (13.0-17.6 kJ mol${ }^{-1}$, Table 2) is obtained for reaction 5. These results indicate that the calculation of $\pi$-stabilization energies serve as a challenging test case for GGA and MGGA functionals.

The HGGAs show better performance than the GGAs and MGGAs. For example, they all result in RMSDs $<8 \mathrm{~kJ} \mathrm{~mol}^{-1}$. The best performing HGGA attain RMSDs of 3.8 (BH\&HLYPD3), 4.5 (BH\&HLYP) and 5.3 (B3LYP-D3) $\mathrm{kJ} \mathrm{mol}^{-1}$. We note that reaction 26 seems to be particularly challenging for most of the HGGA procedures - for 10 out of the 13 considered HGGAs the largest deviation $\left(9.3-14.5 \mathrm{~kJ} \mathrm{~mol}^{-1}\right)$ is obtained for this reaction. 
The RMSDs of the HMGGA procedures span a wide range from 1.6 (BMK-D3) to 8.4 (TPSSh) $\mathrm{kJ} \mathrm{mol}^{-1}$. We note that the exceptional performance of BMK-D3 is also demonstrated by a largest deviation of merely $2.5 \mathrm{~kJ} \mathrm{~mol}^{-1}$, and a near-zero MSD of $+0.2 \mathrm{~kJ} \mathrm{~mol}^{-1}$ suggesting that it is free of systematic bias. Inspection of Table 2 reveals that the optimal percentage of HartreeFock-type exchange seems to be around $\sim 50 \%$. For example, BMK and BMK-D3 (42\% of exact exchange) give RMSDs of 1.6 and $2.1 \mathrm{~kJ} \mathrm{~mol}^{-1}$, respectively. M05-2X (56\% of exact exchange) gives a slightly worse performance, with an RMSD of $2.5 \mathrm{~kJ} \mathrm{~mol}^{-1}$ (note that M06-2X, which involves a similar amount of exact exchange, gives a higher RMSD of $3.5 \mathrm{~kJ} \mathrm{~mol}^{-1}$ ). However, functionals with 25-30\% of Hartree-Fock exchange, such as M05, M06, PW6B95, and B1B95 give significantly higher RMSDs of $6.3-7.7 \mathrm{~kJ} \mathrm{~mol}^{-1}$. We note that the good performance of the HGGAs and HMGGAs with high percentages of Hartree-Fock exchange indicates that the selfinteraction error (also known as the delocalization error) ${ }^{105}$ may play an important role in these systems. This is also indicated by the generally good performance of the RS functionals (vide infra).

The range-separated hybrid-GGAs give reasonably good performance with RMSDs ranging between 3.1 (CAM-B3LYP-D3) and 5.0 (LC- $\omega$ PBE) $\mathrm{kJ} \mathrm{mol}^{-1}$. We note that the good

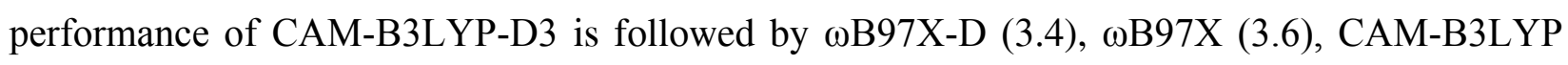
(3.8), and M11 (3.9 kJ mol $\left.{ }^{-1}\right)$.

The double-hybrid functionals show excellent performance with RMSDs ranging between 1.4 (DSD-BLYP) and 4.2 (B2-PLYP) $\mathrm{kJ} \mathrm{mol}^{-1}$ (excluding B2K-PLYP, which was parameterized for thermochemical kinetics and shows very poor performance with an RMSD of $11.0 \mathrm{~kJ} \mathrm{~mol}^{-1} !$ !). ${ }^{84,85}$ We note that B2GP-PLYP gives similar performance to DSD-BLYP with an RMSD of $1.6 \mathrm{~kJ}$ $\mathrm{mol}^{-1}$, and that both procedures attain near-zero MSDs ( -0.1 and $-0.3 \mathrm{~kJ} \mathrm{~mol}^{-1}$, respectively).

Table S5 (Supplementary data) gives an overview of the basis set convergence for the reactions in the DIE60 database. We consider Dunning's cc-pVnZ basis sets ( $n=\mathrm{D}, \mathrm{T}, \mathrm{Q})$. With few exceptions, the functionals converge relatively smoothly and rapidly to the basis set limit such that even the cc-pVDZ basis set gives acceptable results. For example, the RMSDs obtained with the cc-pVDZ basis set are generally higher by $0.1-0.5 \mathrm{~kJ} \mathrm{~mol}^{-1}$ than those obtained with ccpVQZ basis set.

3.3.2. Linear/branched dienes. Table 3 gives the RMSDs over a subset of the DIE60 database involving only linear/branched structures (reactions 1-19, Fig. 1). Comparison of the RMSDs obtained for the linear/branched subset (Table 3) with the RMSDs for the entire DIE60 set (Table 2) reveals that for some functionals the RMSD increases and for some it decreases. However, 
with very few exceptions the changes in the RMSDs between the two sets vary between $0-2 \mathrm{~kJ}$ $\mathrm{mol}^{-1}$. We make the following general observations with regard to the performance of DFT for the linear/branched subset:

$>$ The GGA and MGGA functionals give poor performance with RMSDs ranging between 6.6 and $13.2 \mathrm{~kJ} \mathrm{~mol}^{-1}$. The best performing GGA being BLYP-D3 (RMSD $=6.6 \mathrm{~kJ} \mathrm{~mol}^{-}$ ${ }^{1}$ ), and the best performing MGGA being TPSS-D3 (RMSD $=8.2 \mathrm{~kJ} \mathrm{~mol}^{-1}$ ).

$>$ The performance of the HGGAs for the linear/branched subset is rather similar to their performance over the entire DIE60 set. Where in both cases BH\&HLYP-D3 comes out as the best performer, with RMSDs of $2.5 \mathrm{~kJ} \mathrm{~mol}^{-1}$ (linear/branched subset) and 3.8 (entire DIE60 set) $\mathrm{kJ} \mathrm{mol}^{-1}$.

$>$ A number of HMGGAs show particularly good performance for the linear/branched subset, with the following RMSDs: M05-2X (1.3), M06-2X (1.5), and BMK-D3 (1.6 kJ $\left.\mathrm{mol}^{-1}\right)$.

$>$ The performance of the range-separated functionals for the linear/branched subset is systematically better than it is for the entire set (the RMSDs are smaller by $1.1-3.1 \mathrm{~kJ}$ $\left.\mathrm{mol}^{-1}\right)$. In particular, three functionals give excellent performance, with RMSDs $=0.9$

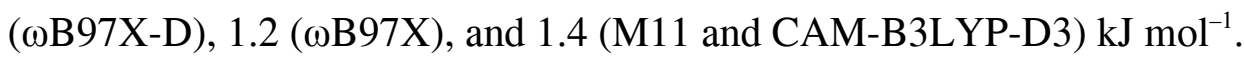

$>$ The performance of the DH procedures for the linear/branched subset is practically the same as it is for the entire DIE60 set. 
Table 3. Statistical analysis for the performance of DFT procedures for subsets of the DIE60 database (RMSDs, $\left.\mathrm{kJ} \mathrm{mol}^{-1}\right)^{a, b}$

\begin{tabular}{|c|c|c|c|c|c|c|c|c|}
\hline \multirow[b]{2}{*}{ Type } & \multirow[b]{2}{*}{ Method } & \multirow{2}{*}{$\begin{array}{c}\text { Linear } \\
\text { All }^{c}\end{array}$} & \multicolumn{6}{|c|}{ Cyclic } \\
\hline & & & $\mathrm{All}^{d}$ & 3-mem ${ }^{e}$ & 3-mem ${ }^{f}$ & 3-mem ${ }^{g}$ & 4-mem ${ }^{h}$ & 5-mem ${ }^{i}$ \\
\hline \multirow[t]{11}{*}{ GGA } & BLYP & 9.2 & 7.9 & 7.6 & 9.4 & 8.7 & 8.2 & 5.9 \\
\hline & BLYP-D3 & 6.6 & 6.7 & 7.0 & 7.8 & 7.5 & 6.1 & 5.2 \\
\hline & B97-D & 8.0 & 7.5 & 6.8 & 9.6 & 8.5 & 6.0 & 5.9 \\
\hline & НСТН407 & 9.5 & 12.0 & 9.4 & 16.5 & 13.9 & 11.7 & 7.4 \\
\hline & PBE & 10.4 & 8.9 & 7.0 & 11.3 & 9.7 & 9.4 & 6.9 \\
\hline & PBE-D3 & 9.0 & 8.4 & 6.9 & 10.7 & 9.3 & 8.5 & 6.4 \\
\hline & BP86 & 10.3 & 8.5 & 7.0 & 10.6 & 9.2 & 9.1 & 6.6 \\
\hline & BP86-D3 & 7.8 & 7.4 & 6.5 & 9.3 & 8.2 & 7.1 & 5.8 \\
\hline & BPW91 & 10.5 & 9.4 & 7.6 & 12.0 & 10.3 & 10.0 & 6.9 \\
\hline & SOGGA11 & 7.6 & 9.9 & 8.5 & 12.5 & 10.9 & 10.8 & 7.0 \\
\hline & N12 & 11.2 & 8.8 & 7.9 & 10.2 & 9.3 & 9.5 & 7.4 \\
\hline \multirow[t]{8}{*}{ MGGA } & M06-L & 12.5 & 11.3 & 7.2 & 15.1 & 12.3 & 12.1 & 8.5 \\
\hline & TPSS & 10.1 & 8.9 & 7.7 & 11.2 & 9.8 & 9.1 & 6.6 \\
\hline & TPSS-D3 & 8.2 & 8.2 & 7.4 & 10.4 & 9.2 & 7.8 & 6.0 \\
\hline & $\tau$-НCТН & 10.4 & 11.0 & 8.9 & 14.9 & 12.6 & 10.8 & 7.1 \\
\hline & VSXC & 13.2 & 8.0 & 7.0 & 7.1 & 7.1 & 7.1 & 9.8 \\
\hline & BB95 & 10.5 & 9.1 & 6.9 & 11.7 & 9.9 & 9.7 & 7.0 \\
\hline & M11-L & 10.5 & 9.6 & 5.0 & 13.5 & 10.7 & 9.7 & 7.1 \\
\hline & MN12-L & 12.0 & 9.7 & 6.2 & 12.3 & 10.1 & 10.2 & 8.4 \\
\hline \multirow[t]{13}{*}{ HGGA } & BH\&HLYP & 3.5 & 4.9 & 3.5 & 7.3 & 5.9 & 3.3 & 2.8 \\
\hline & BH\&HLYP-D3 & 2.5 & 4.3 & 3.1 & 6.5 & 5.3 & 1.6 & 2.6 \\
\hline & B3LYP & 6.9 & 6.5 & 5.7 & 8.5 & 7.4 & 6.3 & 4.4 \\
\hline & B3LYP-D3 & 4.9 & 5.5 & 5.1 & 7.3 & 6.4 & 4.3 & 3.8 \\
\hline & B3P86 & 8.0 & 7.3 & 5.4 & 9.9 & 8.2 & 7.2 & 5.2 \\
\hline & B3PW91 & 7.9 & 7.9 & 5.7 & 10.8 & 9.0 & 7.7 & 5.2 \\
\hline & B3PW91-D3 & 5.4 & 6.8 & 5.1 & 9.7 & 8.0 & 5.6 & 4.2 \\
\hline & PBE0 & 7.3 & 7.4 & 4.8 & 10.5 & 8.5 & 7.0 & 4.8 \\
\hline & PBE0-D3 & 6.0 & 6.8 & 4.5 & 9.9 & 8.0 & 5.8 & 4.2 \\
\hline & B97-1 & 6.3 & 5.5 & 4.7 & 6.8 & 6.0 & 6.0 & 4.2 \\
\hline & B98 & 6.2 & 5.4 & 4.7 & 6.5 & 5.8 & 5.9 & 4.2 \\
\hline & X3LYP & 6.7 & 6.2 & 5.4 & 8.1 & 7.1 & 5.9 & 4.3 \\
\hline & SOGGA11-X & 4.6 & 6.1 & 3.2 & 9.4 & 7.4 & 4.8 & 3.1 \\
\hline \multirow[t]{13}{*}{ HMGGA } & M05 & 5.2 & 8.7 & 4.0 & 13.6 & 10.6 & 7.3 & 4.0 \\
\hline & M05-2X & 1.3 & 2.9 & 1.5 & 4.8 & 3.8 & 0.5 & 1.1 \\
\hline & M06 & 5.9 & 6.9 & 2.6 & 10.8 & 8.3 & 5.3 & 4.2 \\
\hline & M06-2X & 1.5 & 4.2 & 1.8 & 7.0 & 5.4 & 1.8 & 1.5 \\
\hline & M06-HF & 7.6 & 5.1 & 4.3 & 4.7 & 4.5 & 7.1 & 4.9 \\
\hline & BMK & 2.4 & 1.9 & 1.4 & 2.0 & 1.8 & 2.5 & 1.8 \\
\hline & BMK-D3 & 1.6 & 1.6 & 1.0 & 2.0 & 1.6 & 0.7 & 1.8 \\
\hline & B1B95 & 7.1 & 7.3 & 4.5 & 10.5 & 8.4 & 6.9 & 4.7 \\
\hline & B1B95-D3 & 6.1 & 6.7 & 4.4 & 9.8 & 7.9 & 5.4 & 4.3 \\
\hline & TPSSh & 8.8 & 8.2 & 6.6 & 10.8 & 9.2 & 8.1 & 5.8 \\
\hline & $\tau$-HCTHh & 7.4 & 6.3 & 5.3 & 7.8 & 6.8 & 6.9 & 4.9 \\
\hline & PW6B95 & 6.7 & 6.5 & 4.3 & 9.2 & 7.5 & 6.1 & 4.4 \\
\hline & PW6B95-D3 & 6.2 & 6.3 & 4.3 & 9.0 & 7.3 & 5.5 & 4.2 \\
\hline
\end{tabular}




\begin{tabular}{|c|c|c|c|c|c|c|c|c|}
\hline RS & CAM-B3LYP & 2.7 & 4.2 & 2.5 & 6.6 & 5.2 & 3.0 & 2.0 \\
\hline & CAM-B3LYP-D3 & 1.4 & 3.6 & 1.8 & 6.0 & 4.6 & 1.5 & 1.6 \\
\hline & $\mathrm{LC}-\omega \mathrm{PBE}$ & 1.9 & 5.9 & 2.9 & 9.4 & 7.3 & 3.2 & 3.5 \\
\hline & LC- $\omega$ PBE-D3 & 2.4 & 5.5 & 2.6 & 8.9 & 6.9 & 2.1 & 3.3 \\
\hline & $\omega \mathrm{B} 97$ & 2.2 & 4.9 & 2.8 & 7.7 & 6.1 & 1.8 & 3.2 \\
\hline & $\omega B 97 X$ & 1.2 & 4.3 & 1.9 & 6.9 & 5.4 & 1.8 & 2.4 \\
\hline & $\omega \mathrm{B} 97 \mathrm{X}-\mathrm{D}$ & 0.9 & 4.1 & 1.9 & 6.7 & 5.2 & 2.3 & 1.7 \\
\hline & M11 & 1.4 & 4.7 & 3.8 & 7.0 & 5.8 & 1.7 & 2.7 \\
\hline $\mathrm{DH}$ & B2-PLYP & 4.3 & 4.1 & 3.6 & 5.2 & 4.6 & 3.8 & 3.2 \\
\hline & B2-PLYP-D3 & 3.3 & 3.5 & 3.2 & 4.4 & 3.9 & 2.7 & 2.8 \\
\hline & B2GP-PLYP & 1.8 & 1.5 & 1.3 & 1.8 & 1.6 & 0.5 & 1.6 \\
\hline & B2GP-PLYP-D3 & 2.0 & 1.4 & 1.2 & 1.5 & 1.4 & 0.7 & 1.7 \\
\hline & B2K-PLYP & 15.2 & 8.3 & 7.7 & 9.4 & 8.7 & 3.2 & 9.4 \\
\hline & B2T-PLYP & 2.2 & 1.7 & 1.6 & 2.1 & 1.9 & 0.6 & 1.8 \\
\hline & DSD-BLYP & 1.4 & 1.3 & 1.0 & 1.6 & 1.4 & 0.4 & 1.5 \\
\hline & DSD-PBEP86 & 2.5 & 2.8 & 2.0 & 4.0 & 3.2 & 2.5 & 2.1 \\
\hline & DSD-PBEP86-D3 & 1.5 & 2.4 & 2.0 & 3.3 & 2.8 & 1.1 & 1.7 \\
\hline & PWPB95 & 3.9 & 4.1 & 2.4 & 6.0 & 4.8 & 3.6 & 2.5 \\
\hline & PWPB95-D3 & 3.5 & 3.9 & 24 & 59 & 4.7 & 32 & 2.3 \\
\hline
\end{tabular}

${ }^{a}$ Footnotes $a, b$, and $c$ to Table 2 apply here. ${ }^{b}$ The reactions are shown in Fig. $1 .{ }^{c}$ All reactions involving linear/branched structures (reactions 1-19). ${ }^{d}$ All reactions involving cyclic structures (reactions 20-60). ${ }^{e}$ Reactions in which the number cyclic $\mathrm{sp}^{2}$ carbons is the same on the two sides of the reaction. ${ }^{f}$ Reactions in which the number cyclic $\mathrm{sp}^{2}$ carbons is not balanced on the two sides of the reaction (Fig. 2). ${ }^{g}$ All reactions involving 3-membered rings (reactions 20-42). ${ }^{h}$ All reactions involving 4-membered rings (reactions 43-48). ${ }^{i}$ All reactions involving 5membered rings (reactions 49-60).

3.3.3. Cyclic dienes. Table 3 gives the RMSDs over the reactions that involve only the cyclic structures in the DIE60 database (reactions 20-60, Fig. 1). We start by making the following general observations:

With very few exceptions (most notably HCTH407 and SOGGA11), the performance of all of the GGA and MGGA functionals is better for the cyclic subset than for the linear/branched subset.

In contrast, the performance of the range-separated procedures is systematically better for the linear/branched subset.

Overall, the RMSDs obtained for the cyclic subset differ by about 0-2 $\mathrm{kJ} \mathrm{mol}^{-1}$ (in absolute value) from those obtained for the linear/branched subset. Noticeable exception are: (i) VSXC, for which the RMSDs over the cyclic subset is smaller than those over the linear/branched subset by $5.2 \mathrm{~kJ} \mathrm{~mol}^{-1}$; and (ii) M05 and LC- $\omega \mathrm{PBE}$, for which the RMSDs over the cyclic subset are larger than those over the linear/branched subset by 3.5 and 4.0 $\mathrm{kJ} \mathrm{mol}^{-1}$, respectively. 
The last three columns of Table 3 give the RMSDs for the subset of cyclic reactions that involve only 3-membered rings, 4-membered rings, and 5-membered rings. It is clear the subset of the 3-membered rings is the most taxing subset, namely, the performance of most of the GGA, MGGA, HGGA, and HMGGA functionals deteriorates along the series: 5-membered rings $\rightarrow$ 4membered rings $\rightarrow 3$-membered rings. It is instructive to further divide the subset of the 3membered rings into two subsets: (i) reactions in which the reactants and products have the same number of $\mathrm{sp}^{2}$ carbons in the ring, and (ii) reactions in which the number of $\mathrm{sp}^{2}$ carbons in the ring is not balanced on the two sides of the reaction (Fig. 2). In the following we will refer to these subsets as subsets (i) and (ii). In subset (i) the strain energy is expected to be similar on both sides of the reaction, whilst in subset (ii) the strain energy is expected to be larger on the reactants side. This is due to the strain energy associated with the presence of an extra $\mathrm{sp}^{2}$ carbon in a highly strained 3-membered ring (see also discussion in Section 3.2). The RMSDs for these two subsets are given in Table 3. It is convenient for the following discussion to define: $\triangle \mathrm{RMSD}$ $=\mathrm{RMSD}_{\text {subset ii }}-\mathrm{RMSD}_{\text {subset } \mathrm{i}}$. The performance of almost all of the GGA, MGGA, HGGA, HMGGA, and range-separated functionals is significantly better for subset (i) than for subset (ii). For example, for 42 out of the 53 considered conventional DFT functionals, $\triangle$ RMSD $=2.1-9.6$ $\mathrm{kJ} \mathrm{mol}^{-1}$. The DH functionals, on the other hand, show a more balanced performance for the two subsets with $\triangle \mathrm{RMSD} \leq 2.0 \mathrm{~kJ} \mathrm{~mol}^{-1}$ (with the exception of PWPB95). We offer the following general observations with regard to the performance of the conventional DFT procedures:

$>$ For the GGAs the $\triangle$ RMSDs vary between 0.8 (BLYP-D3) and 7.1 (HCTH407) kJ mol ${ }^{-1}$.

$>$ The MGGA have $\triangle$ RMSDs between 3.0 (TPSS-D3) and 8.5 (M11-L) kJ mol ${ }^{-1}$ (with the exception of VSXC for which $\triangle \mathrm{RMSD}$ is essentially nil).

$>$ The $\triangle$ RMSDs for the HGGAs vary between 1.8 (B98) and 6.2 (SOGGA11) kJ mol ${ }^{-1}$.

$>$ Three HMGGA procedures show similar performance for the two subsets with $\triangle \mathrm{RMSD}=$ 0.4 (M06-HF), 0.6 (BMK), and 1.0 (BMK-D3) kJ mol ${ }^{-1}$. Of these, both BMK and BMKD3 give excellent performance with RMSDs $=1.0-2.0 \mathrm{~kJ} \mathrm{~mol}^{-1}$. For the rest of the HMGGA the $\triangle$ RMSDs vary between 2.5 ( $\tau$-HCTHh) and $9.6(\mathrm{M} 05) \mathrm{kJ} \mathrm{mol}^{-1}$.

As discussed in Section 3.2, all the reactions in subset (ii) are exothermic. However, inspection of the DFT reaction energies reveals that a large number of DFT procedures (83\% of the conventional DFT functionals) predict that reaction 36 is endothermic (Fig. 2). Table 4 gives the W2-F12 and the DFT reaction energies for this taxing isomerization reaction. At the W2-F12 level we obtain a reaction energy $\left(\Delta E_{e}\right)$ of $-7.7 \mathrm{~kJ} \mathrm{~mol}^{-1}$. The DFT reaction energies span a wide range, from -9.5 (B2T-PLYP) to $+10.3(\mathrm{M} 06-\mathrm{L}) \mathrm{kJ} \mathrm{mol}^{-1}$. Only 20 out of the 64 considered 
functionals predict that this reaction is exothermic, and $85 \%$ of the functionals deviate by 6.0 $18.0 \mathrm{~kJ} \mathrm{~mol}^{-1}$ from the W2-F12 reaction energy. We begin by noting that all of the DH functionals predict that this reaction is exothermic, however, B2-PLYP, PWPB95, and B2KPLYP give reactions energies that are far from the W2-F12 value (namely, they predict $\Delta E_{e}$ to be between -2.4 and $-0.5 \mathrm{~kJ} \mathrm{~mol}^{-1}$ ). Of the conventional functionals, notable procedures that perform poorly predict the following reaction energies: +5.0 (M06), +6.3 (M05), +7.6 ( $\tau$-HCTH), +8.0 (M11-L), +8.1 (MN12-L), +9.1 (HCTH407), and +10.3 (M06-L) kJ mol ${ }^{-1}$. On the other hand, BMK-D3 gives a reaction energy which is spot-on the W2-F12 value, and other good performers give reaction energies of: -8.9 (B2GP-PLYP), -8.8 (DSD-BLYP), and -8.5 (M06-HF) $\mathrm{kJ} \mathrm{mol}^{-1}$.

Table 4. DFT reaction energies for reaction 36 (Fig. 2), for which $83 \%$ of the considered DFT functionals predict the wrong sign for the reaction energy (the tabulated values are reaction energies in $\left.\mathrm{kJ} \mathrm{mol}^{-1}\right)^{a, b}$

\begin{tabular}{llc}
\hline Type & Method & $\Delta E_{e}$ \\
\hline \multirow{4}{*}{ GGA } & W2-F12 & $-\mathbf{7 . 7}$ \\
& BLYP & 0.0 \\
& BLYP-D3 & $-\mathbf{1 . 4}$ \\
& B97-D & 1.8 \\
& HCTH407 & 9.1 \\
& PBE & 3.7 \\
& PBE-D3 & 3.2 \\
& BP86 & 2.7 \\
& BP86-D3 & 1.4 \\
& BPW91 & 4.2 \\
& SOGGA11 & 2.5 \\
MGGA & N12 & 2.0 \\
& M06-L & 10.3 \\
& TPSS & 3.5 \\
& TPSS-D3 & 2.6 \\
& $\tau$-HCTH & 7.6 \\
& VSXC & 0.3 \\
& BB95 & 3.9 \\
& M11-L & 8.0 \\
HGGA & MN12-L & 8.1 \\
& BH\&HLYP & 1.1 \\
& BH\&HLYP-D3 & 0.3 \\
& B3LYP & 1.0 \\
& B3LYP-D3 & $-\mathbf{0 . 3}$ \\
& B3P86 & 3.6 \\
& B3PW91 & 4.4 \\
& B3PW91-D3 & 3.1 \\
& PBE0 & 4.5 \\
& &
\end{tabular}




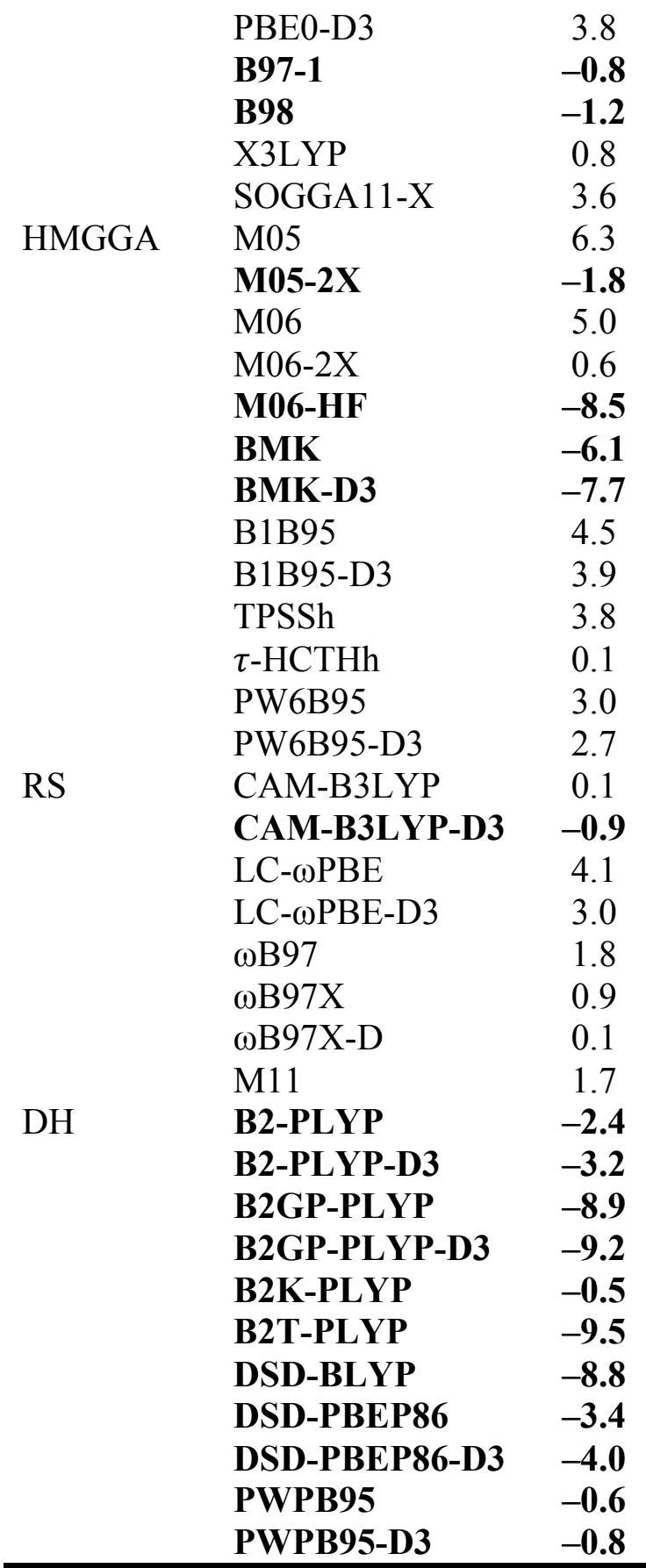

${ }^{a}$ Footnotes $a$ and $c$ to Table 2 apply here. ${ }^{b}$ The functionals that predict the correct (negative) sign are given in bold. ${ }^{c}$ Reference reaction energy from W2-F12 theory.

3.4. Performance of composite and lower-level ab initio procedures for the isomerization reactions in the DIE60 database. Table 5 gives an overview of the performance of the composite G4, G4(MP2), G4(MP2)-6X, CBS-QB3, and CBS-APNO procedures, as well as several ab initio methods (e.g., MP2, MP2.5, MP3, MP4, SCS-MP2, SCS-MP3, CCSD and $\operatorname{CCSD}(\mathrm{T}))$. All the composite procedures give excellent performance with RMSDs below $1.7 \mathrm{~kJ}$ $\mathrm{mol}^{-1}$. The $\mathrm{G} n$-type procedures give similar performance, with RMSDs ranging between $1.3(\mathrm{G} 4)$ and 1.7 (G4(MP2)) $\mathrm{kJ} \mathrm{mol}^{-1}$. The CBS procedures show slightly better performance, with 
RMSDs of 0.9 (CBS-QB3) and 1.1 (CBS-APNO) $\mathrm{kJ} \mathrm{mol}^{-1}$. We note that whilst the Gn-type procedures tend to systematically underestimate the reaction energies (with $-\mathrm{MSDs} \approx \mathrm{MADs}=$ 1.1-1.5 $\mathrm{kJ} \mathrm{mol}^{-1}$ ), the CBS procedures give near-zero MSDs indicating that they are less prone to systematic bias. It is clear that the composite procedures do not have difficulty with the reaction energies that are problematic for the DFT functionals, the largest deviations being well below the 'chemical accuracy' threshold (Table 5).

We now turn our attention to the performance of the standard wavefunction methods in conjunction with the cc-pVnZ basis sets ( $n=\mathrm{D}, \mathrm{T}$, and Q) (Table 5). We start by noting that practically all the ab initio methods converge fairly rapidly to the basis set limit. For example, for the methods for which we have cc-pVQZ results (HF, MP2, SCS-MP2, MP2.5, MP3, and SCSMP3) the difference in the overall RMSDs between the cc-pVQZ and cc-pVTZ are equal to or smaller than $0.1 \mathrm{~kJ} \mathrm{~mol}^{-1}$ (in absolute value). In the following discussion we will use the results obtained with the cc-pVQZ for the abovementioned methods, and the cc-pVTZ basis set for all the rest. Nevertheless, it is worth mentioning that even the cc-pVDZ basis set does not perform too badly, considering its low computational cost. Specifically, the difference in the overall RMSDs between the cc-pVTZ and cc-pVDZ basis sets are equal to or smaller than $0.6 \mathrm{~kJ} \mathrm{~mol}^{-1}$ (in absolute value), with the exception of $\operatorname{CCSD}(\mathrm{T})$ for which it is $0.9 \mathrm{~kJ} \mathrm{~mol}^{-1}$ (Table 5).

We start by noting that HF theory $\left(\mathrm{RMSD}=5.1 \mathrm{~kJ} \mathrm{~mol}^{-1}\right)$ actually outperforms all of the considered GGA, MGGA, and HGGA functionals (with the exceptions of BH\&HLYP and BH\&HLYP-D3 which give RMSDs of 4.5 and $3.8 \mathrm{~kJ} \mathrm{~mol}^{-1}$, respectively). The conventional DFT functionals that consistently outperform HF theory are the RS procedures, and the HMGGAs with $\sim 50 \%$ of exact exchange (e.g., BMK, M05-2X, and M06-2X). Second-order Møller-Plesset perturbation theory (MP2) results in an RMSD of $2.7 \mathrm{~kJ} \mathrm{~mol}^{-1}$ (the same RMSD as DSDPBEP86). However, this RMSD is reduced to merely $1.0 \mathrm{~kJ} \mathrm{~mol}^{-1}$ when the same-spin and opposite-spin components of the MP2 correlation energy are scaled, as in the SCS-MP2 procedure. Inclusion of higher-order excitations in procedures such as MP2.5, MP3, SCS-MP3, and MP4 results in RMSDs ranging between $0.9-1.2 \mathrm{~kJ} \mathrm{~mol}^{-1}$. Thus, the increase in the computational cost (relative to SCS-MP2) does not seem to warrant their use. The CCSD method attains a somewhat disappointing RMSD of $2.0 \mathrm{~kJ} \mathrm{~mol}^{-1}$, and the its spin-component-scaled variants give even larger RMSDs. The $\operatorname{CCSD}(\mathrm{T})$ method attains RMSDs of 0.7 and $1.6 \mathrm{~kJ} \mathrm{~mol}^{-1}$ in conjunction with the cc-pVTZ and cc-pVDZ basis sets, respectively. It is of interest to assess the performance of the $\operatorname{CCSD}(\mathrm{T})$ method using an additivity-based approach in which the $\operatorname{CCSD}(\mathrm{T}) / \mathrm{CBS}$ energy is estimated from the CCSD(T)/cc-pVDZ energy and an MP2-based basisset-correction term $(\triangle \mathrm{MP} 2=\mathrm{MP} 2 / \mathrm{cc}-\mathrm{pV}\{\mathrm{T}, \mathrm{Q}\} \mathrm{Z}-\mathrm{MP} 2 / \mathrm{cc}-\mathrm{pVDZ}$, where the MP2/cc-pV $\{\mathrm{T}, \mathrm{Q}\} \mathrm{Z}$ 
energy is extrapolated to the basis-set limit with an extrapolation exponent of 3). ${ }^{106}$ This costeffective approach, which has been shown to give good results for noncovalent interactions, ${ }^{6,107,108,109,110}$ results in an RMSD of merely $0.5 \mathrm{~kJ} \mathrm{~mol}^{-1}$ and in fact outperforms all of the standard $\mathrm{ab}$ initio and composite procedures in Table 5.

Table 5 Statistical analysis for the performance of composite and standard ab initio methods for the calculation of the diene isomerization energies in the DIE60 database (in kJ mol$\left.{ }^{-1}\right)^{a}$

\begin{tabular}{|c|c|c|c|c|c|}
\hline Basis set & Methods & RMSD & MAD & MSD & LD \\
\hline \multirow{11}{*}{ cc-pVQZ } & G4 & 1.3 & 1.1 & -1.0 & $2.6(10)$ \\
\hline & G4(MP2) & 1.7 & 1.5 & -1.5 & $3.2(36)$ \\
\hline & G4(MP2)-6X & 1.4 & 1.1 & -1.1 & $3.3(36)$ \\
\hline & CBS-QB3 & 0.9 & 0.7 & -0.3 & $2.6(32)$ \\
\hline & CBS-APNO & 1.1 & 0.9 & 0.3 & $2.8(32)$ \\
\hline & $\mathrm{HF}$ & 5.1 & 3.9 & -0.8 & $11.0(\mathbf{3 0})$ \\
\hline & MP2 & 2.7 & 2.2 & 2.2 & $8.1(\mathbf{5 0})$ \\
\hline & SCS-MP2 & 1.0 & 0.6 & 0.3 & $4.7(22)$ \\
\hline & MP2.5 & 1.0 & 0.7 & 0.7 & $3.2(\mathbf{5 0})$ \\
\hline & MP3 & 1.2 & 1.1 & -0.8 & $2.0(13)$ \\
\hline & SCS-MP3 & 0.9 & 0.6 & -0.1 & $3.6(22)$ \\
\hline \multirow[t]{12}{*}{ cc-pVTZ } & $\mathrm{HF}$ & 5.0 & 3.9 & -0.7 & $11.1(\mathbf{3 0})$ \\
\hline & MP2 & 2.8 & 2.3 & 2.3 & $7.8(\mathbf{5 7})$ \\
\hline & SCS-MP2 & 1.1 & 0.8 & 0.3 & $4.9(22)$ \\
\hline & MP2.5 & 1.0 & 0.8 & 0.8 & $2.9(54)$ \\
\hline & MP3 & 1.1 & 1.0 & -0.7 & $2.5(\mathbf{1 0})$ \\
\hline & SCS-MP3 & 1.0 & 0.7 & 0.0 & $3.9(22)$ \\
\hline & MP4 & 1.2 & 0.9 & 0.9 & $3.0(22)$ \\
\hline & CCSD & 2.0 & 1.7 & -1.6 & $4.7(\mathbf{5 0})$ \\
\hline & SCS-CCSD & 2.3 & 2.1 & -2.1 & $4.2(\mathbf{6 0})$ \\
\hline & SCS(MI)CCSD & 2.7 & 2.2 & 2.1 & $8.0(\mathbf{5 0})$ \\
\hline & $\operatorname{CCSD}(\mathrm{T})$ & 0.7 & 0.6 & -0.3 & $1.6(\mathbf{5 0})$ \\
\hline & $\operatorname{CCSD}(\mathrm{T}) / \mathrm{CBS}^{b}$ & 0.5 & 0.4 & -0.4 & $1.2(35)$ \\
\hline \multirow[t]{11}{*}{ cc-pVDZ } & $\mathrm{HF}$ & 4.6 & 3.4 & -0.4 & $10.6(34)$ \\
\hline & MP2 & 2.9 & 2.2 & 2.1 & $8.5(57)$ \\
\hline & SCS-MP2 & 1.7 & 1.4 & 0.3 & $6.0(22)$ \\
\hline & MP2.5 & 1.5 & 1.2 & 0.6 & $4.1(22)$ \\
\hline & MP3 & 1.4 & 1.1 & -0.8 & $4.4(\mathbf{1 0})$ \\
\hline & SCS-MP3 & 1.6 & 1.3 & -0.1 & $5.1(22)$ \\
\hline & MP4 & 1.6 & 1.4 & 0.7 & $3.9(22)$ \\
\hline & CCSD & 2.4 & 2.0 & -1.8 & $5.9(\mathbf{1 0})$ \\
\hline & SCS-CCSD & 2.5 & 1.7 & -0.2 & $6.5(34)$ \\
\hline & SCS(MI)CCSD & 2.8 & 2.4 & -2.4 & $5.1(\mathbf{1 0})$ \\
\hline & $\operatorname{CCSD}(\mathrm{T})$ & 1.6 & 1.3 & -0.5 & $3.6(\mathbf{1 0})$ \\
\hline
\end{tabular}

${ }^{a}$ Footnote $b$ to Table 2 applies here. ${ }^{b} \operatorname{CCSD}(\mathrm{T}) / \mathrm{CBS} \approx \operatorname{CCSD}(\mathrm{T}) / \mathrm{cc}-\mathrm{pVDZ}+\mathrm{MP} 2 / \mathrm{cc}-\mathrm{pV}\{\mathrm{T}, \mathrm{Q}\} Z-\mathrm{MP} 2 / \mathrm{cc}-\mathrm{pVDZ}$. 


\section{Conclusions}

We have obtained benchmark isomerization energies by means of the high-level W2-F12 composite thermochemistry protocol (or W1-F12, for the largest systems), for a diverse set of isomerization reactions involving double-bond migration in conjugated dienes. We use these benchmark diene isomerization energies (a.k.a. the DIE60 database) to evaluate the performance of a variety of contemporary density functional theory and ab initio procedures for the calculation of $\pi$-conjugation stabilization energies. With regard to the performance of the DFT and DHDFT procedures for the DIE60 dataset we make the following observations:

$>$ The calculation of $\pi$-stabilization energies serve as a challenging test for most conventional DFT procedures, in particular the GGA and MGGA functionals.

$>$ With few exceptions, conventional DFT methods (rungs 1-4 of Jacob's Ladder) yield relatively large RMSDs ranging between $4.5-11.7 \mathrm{~kJ} \mathrm{~mol}^{-1}$. The DHDFT methods, on the other hand, show good performance with RMSDs well below the 'chemical accuracy' threshold.

$>$ All the considered GGA and MGGA functionals give relatively poor performance with RMSDs ranging between 6.6 and $13.2 \mathrm{~kJ} \mathrm{~mol}^{-1}$. The best performing GGA being BLYPD3 $\left(\right.$ RMSD $\left.=6.6 \mathrm{~kJ} \mathrm{~mol}^{-1}\right)$, and the best performing MGGA being TPSS-D3 $(\mathrm{RMSD}=$ $8.2 \mathrm{~kJ} \mathrm{~mol}^{-1}$ ).

$>$ The HGGAs show somewhat better performance with RMSDs ranging between 3.8 (BH\&HLYP-D3) and 7.9 (B3PW91) $\mathrm{kJ} \mathrm{mol}^{-1}$. We note that the popular B3LYP-D3 comes in as the third best performer with an RMSD of $5.3 \mathrm{~kJ} \mathrm{~mol}^{-1}$.

$>$ The RMSDs of the HMGGA procedures span a wide range from 1.6 (BMK-D3) to 8.4 (TPSSh) $\mathrm{kJ} \mathrm{mol}^{-1}$. The best performing HMGGA (BMK-D3) shows exceptional performance with a largest deviation of merely $2.5 \mathrm{~kJ} \mathrm{~mol}^{-1}$ and a near-zero MSD of +0.2 $\mathrm{kJ} \mathrm{mol}^{-1}$. Other HMGGAs that perform well are (RMSDs are given in parenthesis): BMK (2.1), M05-2X (2.5), and M06-2X (3.5 kJ mol-1). All the other HMGGAs give RMSD $\geq$ $6.0 \mathrm{~kJ} \mathrm{~mol}^{-1}$.

$>$ The range-separated procedures give reasonably good performance with RMSDs varying

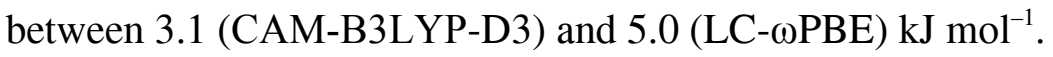

$>$ The double-hybrid procedures give excellent performance. The best performing functionals are: DSD-BLYP (1.4) and B2GP-PLYP $\left(1.6 \mathrm{~kJ} \mathrm{~mol}^{-1}\right)$.

With regard to the performance of the composite and ab initio procedures, we draw the following conclusions: 
$>$ The composite procedures show excellent performance with RMSDs ranging between 0.9 (CBS-QB3) and 1.7 (G4(MP2)) $\mathrm{kJ} \mathrm{mol}^{-1}$.

$>$ The standard ab initio procedures also show good performance with SCS-MP2 offering the best performance-to-computational-cost ratio $\left(\mathrm{RMSD}=1.1\right.$ and $1.0 \mathrm{~kJ} \mathrm{~mol}^{-1}$, respectively, in conjunction with the cc-pVTZ and cc-pVQZ basis sets).

Estimating the CCSD(T)/CBS energy from the CCSD(T)/cc-pVDZ energy and adding an MP2-based basis-set-correction term results in an RMSD of only $0.5 \mathrm{~kJ} \mathrm{~mol}^{-1}$. Remarkably, this simple and cost-effective procedure outperforms all of the considered ab initio and composite procedures.

\section{Appendix A. Supplementary data}

Comparison of W1-F12 and W2-F12 reaction energies for the isomerization reactions in DIE60 database (Table S1); diagnostics indicating the importance of nondynamical correlation effects for the species involved in the DIE60 database (Table S2); experimental heats of formation $\left(\Delta H_{f, 298}\right)$ for the species involved in reactions 1, 2, and 6 (Table S3); diagonal Born-Oppenheimer corrections for the reactions in DIE60 database (Table S4); overview of the basis set convergence of the DFT procedures (Table S5); B3LYP-D3/cc-pVTZ optimized geometries for all the species considered in the present work (Table S6); and full references for Ref. 22 (Molpro 2012), Ref. 43 (CFOUR), and Ref. 54 (Gaussian 09). For the convenience of the reader the Supplementary data also includes a directory (DIE60_input_files_and_script.zip) with the Gaussian input files for the species involved in the DIE60 database and a perl script that calculates the reaction energies and the error statistics from our Wn-F12 reference values. Supplementary data associated with this article can be found, in the online version, at http://dx.doi.org/10.1016/j.cplett.2014.xx.xxx.

\section{Acknowledgments}

Dedicated to Professor Mark A. Spackman on the occasion of his 60th birthday. We gratefully acknowledge the generous allocation of computing time from the National Computational Infrastructure (NCI) National Facility, and the support of iVEC through the use of advanced computing resources located at iVEC@UWA, the provision of an International Postgraduate Research Scholarship (to L-J.Y.), and an Australian Research Council (ARC) Discovery Early Career Researcher Award (to A.K., project number: DE140100311). We would also like to thank the reviewers for helpful comments. 


\section{References}

${ }^{1}$ A. E. Mattsson, Science 298 (2002) 759.

${ }^{2}$ A. J. Cohen, P. Mori-Sánchez, W. Yang, Chem. Rev. 112 (2012) 289.

${ }^{3}$ J. P. Perdew, K. Schmidt, In Density Functional Theory and its Application to Materials; V. Van Doren, C. Van Alsenoy, P. Geerlings, Eds.; AIP Conference Proceedings, 577 (2011) 1.

${ }^{4}$ L. Goerigk, S. Grimme, J. Chem. Theory Comput. 7 (2011) 291.

${ }^{5}$ A. Karton, S. Daon, J. M. L. Martin, Chem. Phys. Lett. 510 (2011) 165.

${ }^{6}$ L. Goerigk, A. Karton, J. M. L. Martin, L. Radom Phys. Chem. Chem. Phys. 15 (2013) 7028.

${ }^{7}$ S. E. Wheeler, K. N. Houk, P. V. R. Schleyer, W. D. Allen, J. Am. Chem. Soc. 131 (2009) 2547.

${ }^{8}$ M. D. Wodrich, C. Corminboeuf, S. E. Wheeler, J. Phys. Chem. A 116 (2012) 3436.

${ }^{9}$ S. E. Wheeler, WIREs Comput. Mol. Sci. 2 (2012) 204.

${ }^{10}$ A. Karton, D. Gruzman, J. M. L. Martin, J. Phys. Chem. A 113 (2009) 8434.

${ }^{11}$ R. O. Ramabhadran, K. Raghavachari, J. Chem. Theory Comput. 7 (2011) 2094.

${ }^{12}$ R. J. O'Reilly, A. Karton, L. Radom, Int. J. Quantum Chem. 112 (2012) 1862.

${ }^{13}$ E. I. Izgorodina, M. L. Coote, L. Radom, J. Phys. Chem. A 109 (2005) 7558.

${ }^{14}$ S. Grimme, Org. Lett. 12 (2010) 4670.

${ }^{15}$ A. Karton, J. M. L. Martin, Mol. Phys. 110 (2012) 2477.

${ }^{16}$ S. Grimme, Angew. Chem. Int. Ed. 45 (2006) 4460.

${ }^{17}$ S. Grimme, M. Steinmetz, M. Korth, J. Org. Chem. 72 (2007) 2118.

${ }^{18}$ M. D. Wodrich, C. Corminboeuf, P. V. R. Schleyer, Org. Lett. 8 (2006) 3631.

${ }^{19}$ M. D. Wodrich, C. Corminboeuf, P. R. Schreiner, A. A. Fokin, P. v. R. Schleyer, Org. Lett. 9 (2006) 1851.

${ }^{20}$ P. R. Schreiner, Angew. Chem. Int. Ed. 46 (2007) 4217.

${ }^{21}$ A. Karton, J. M. L. Martin, J. Chem. Phys. 136 (2012) 124114

${ }^{22}$ MOLPRO is a package of ab initio programs written by H.-J. Werner, P. J. Knowles, G. Knizia, F. R. Manby, M. Schütz, P. Celani, T. Korona, R. Lindh, A. Mitrushenkov, G. Rauhut, et al. See: http:www.molpro.net.

${ }^{23}$ J. M. L. Martin, G. Oliveira, J. Chem. Phys. 111 (1999) 1843.

${ }^{24}$ A. Karton, E. Rabinovich, J. M. L. Martin, B. Ruscic, J. Chem. Phys. 125 (2006) 144108.

${ }^{25}$ K. A. Peterson, D. Feller, D. A. Dixon, Theor. Chem. Acc. 131 (2012) 1079.

${ }^{26}$ T. Helgaker, W. Klopper, D. P. Tew, Mol. Phys. 106 (2008) 2107.

${ }^{27}$ A. Karton, I. Kaminker, J. M. L. Martin, J. Phys. Chem. A 113 (2009) 7610.

${ }^{28}$ R. O. Ramabhadran, K. Raghavachari, J. Phys. Chem. A 116 (2012) 7531.

${ }^{29}$ C. Hättig, W. Klopper, A. Köhn, D. P. Tew, Chem. Rev. 112 (2012) 4.

${ }^{30}$ K. A. Peterson, T. B. Adler, H.-J. Werner, J. Chem. Phys. 128 (2008) 084102.

${ }^{31}$ J. G. Hill, K. A. Peterson, G. Knizia, H.-J. Werner, J. Chem. Phys. 131 (2009) 194105.

32 J. Noga, S. Kedžuch, J. Šimunek, J. Chem. Phys. 127 (2007) 034106.

${ }^{33}$ G. Knizia, H.-J. Werner, J. Chem. Phys. 128 (2008) 154103.

${ }^{34}$ T. B. Adler, G. Knizia, H.-J. Werner, J. Chem. Phys. 127 (2007) 221106.

${ }^{35}$ G. Knizia, T. B. Adler, H.-J. Werner, J. Chem. Phys. 130 (2009) 054104.

${ }^{36}$ S. Ten-no, J. Noga, WIREs Comput. Mol. Sci. 2 (2012) 114.

${ }^{37}$ S. Ten-no, Chem. Phys. Lett. 398 (2004) 56.

${ }^{38}$ H.-J. Werner, T. B. Adler, F. R. Manby, J. Chem. Phys. 126 (2007) 164102.

${ }^{39}$ K. A. Peterson, T. H. Dunning, J. Chem. Phys. 117 (2002) 10548.

${ }^{40}$ M. Douglas, N. M. Kroll, Ann. Phys. 82 (1974) 89.

${ }^{41}$ B. A. Hess, Phys. Rev. A 33 (1986) 3742.

${ }^{42}$ W. A. de Jong, R. J. Harrison, D. A. Dixon, J. Chem. Phys. 114 (2001) 48. 
${ }^{43}$ CFOUR, a quantum chemical program package written by J. F. Stanton, J. Gauss, M. E. Harding, P. G. Szalay, with contributions from A. A. Auer, R. J. Bartlett, U. Benedikt, C. Berger, D. E. Bernholdt, Y. J. Bomble, O. Christiansen, et al. See: http://www.cfour.de.

${ }^{44}$ A. Karton, L.-J. Yu, M. K. Kesharwani, J. M. L. Martin Theor. Chem. Acc 133 (2014) 1483.

${ }^{45}$ T. H. Dunning, J. Chem. Phys. 90 (1989) 1007.

${ }^{46}$ R. A. Kendall, T. H. Dunning, Jr., R. J. Harrison, J. Chem. Phys. 96 (1992) 6796.

${ }^{47}$ C. Lee, W. Yang, R. G. Parr, Phys. Rev. B 37 (1988) 785.

${ }^{48}$ A. D. Becke, J. Chem. Phys. 98 (1993) 5648.

${ }^{49}$ P. J. Stephens, F. J. Devlin, C. F. Chabalowski, M. J. Frisch, J. Phys. Chem. 98 (1994) 11623.

${ }^{50}$ S. Grimme, S. Ehrlich, L. Goerigk, J. Comput. Chem. 32 (2011) 1456.

${ }^{51}$ S. Grimme, J. Antony, S. Ehrlich and H. Krieg, J. Chem. Phys. 132 (2010) 154104.

${ }^{52}$ S. Grimme, WIREs Comput. Mol. Sci. 1 (2011) 211.

${ }^{53}$ A. D. Becke, E. R. Johnson, J. Chem. Phys. 123 (2005) 154101.

${ }^{54}$ M. J. Frisch, G. W. Trucks, H. B. Schlegel, G. E. Scuseria, M. A. Robb, J. R. Cheeseman, G. Scalmani, V. Barone, B. Mennucci, G. A. Petersson, et al. Gaussian 09, Revision D.01; Gaussian, Inc.: Wallingford CT, 2009.

${ }^{55}$ J. P. Perdew, A. Ruzsinszky, J. Tao, V. N. Staroverov, G. E. Scuseria, G. I. Csonka, J. Chem. Phys. 123 (2005) 062201.

${ }^{56}$ A. D. Becke, Phys. Rev. A 38 (1988) 3098.

${ }^{57}$ S. Grimme, J. Comp. Chem. 27 (2006) 1787.

${ }^{58}$ A. D. Boese, N. C. Handy, J. Chem. Phys. 114 (2001) 5497.

${ }^{59}$ J. P. Perdew, K. Burke, M. Ernzerhof, Phys. Rev. Lett. 77 (1996) 3865; ibid Phys. Rev. Lett. 78 (1997) 1396.

${ }^{60}$ J. P. Perdew, Phys. Rev. B 33 (1986) 8822.

${ }^{61}$ J. P. Perdew, J. A. Chevary, S. H. Vosko, K. A. Jackson, M. R. Pederson, D. J. Singh, C. Fiolhais, Phys. Rev. B 46 (1992) 6671.

${ }^{62}$ R. Peverati, Y. Zhao and D. G. Truhlar, J. Phys. Chem. Lett. 2 (2011) 1991.

${ }^{63}$ R. Peverati, D. G. Truhlar, J. Chem. Theory and Comput. 8 (2012) 2310.

${ }^{64}$ Y. Zhao, D. G. Truhlar, J. Chem. Phys. 125 (2006) 194101.

65 J. M. Tao, J. P. Perdew, V. N. Staroverov, G. E. Scuseria, Phys. Rev. Lett. 91 (2003) 146401.

${ }^{66}$ A. D. Boese, N. C. Handy, J. Chem. Phys. 116 (2002) 9559.

${ }^{67}$ T. van Voorhis, G. E. Scuseria, J. Chem. Phys. 109 (1998) 400.

${ }^{68}$ A. D. Becke, J. Chem. Phys. 104 (1996) 1040.

${ }^{69}$ R. Peverati, D. G. Truhlar, J. Phys. Chem. Lett. 3 (2012) 117.

${ }^{70}$ R. Peverati, D. G. Truhlar, Phys. Chem. Chem. Phys. 10 (2012) 13171.

${ }^{71}$ A. D. Becke, J. Chem. Phys. 98 (1993) 1372.

${ }^{72}$ C. Adamo, V. Barone, J. Chem. Phys. 110 (1999) 6158.

${ }^{73}$ F. A. Hamprecht, A. J. Cohen, D. J. Tozer, N. C. Handy, J. Chem. Phys. 109 (1998) 6264.

${ }^{74}$ H. L. Schmider, A. D. Becke, J. Chem. Phys. 108 (1998) 9624.

${ }^{75}$ X. Xu, Q. Zhang, R. P. Muller, W. A. Goddard, J. Chem. Phys. 122 (2005) 014105.

${ }^{76}$ R. Peverati, D. G. Truhlar, J. Chem. Phys. 135 (2011) 191102

${ }^{77}$ Y. Zhao, N. E. Schultz, D. G. Truhlar, J. Chem. Phys. 123 (2005) 161103.

${ }^{78}$ Y. Zhao, N. E. Schultz, D. G. Truhlar, J. Chem. Theory and Comput. 2 (2006) 364.

${ }^{79}$ Y. Zhao, D. G. Truhlar, Theor. Chem. Acc. 120 (2008) 215.

${ }^{80}$ A. D. Boese, J. M. L. Martin, J. Chem. Phys. 121 (2004) 3405.

${ }^{81}$ V. N. Staroverov, G. E. Scuseria, J. Tao, J. P. Perdew, J. Chem. Phys. 119 (2003) 12129.

${ }^{82}$ Y. Zhao, D. G. Truhlar, J. Phys. Chem. A 109 (2005) 5656.

${ }^{83}$ S. Grimme, J. Chem. Phys. 124 (2006) 034108. 
${ }^{84}$ A. Karton, A. Tarnopolsky, J.-F. Lamere, G. C. Schatz, J. M. L. Martin, J. Phys. Chem. A 112 (2008) 12868.

${ }^{85}$ A. Tarnopolsky, A. Karton, R. Sertchook, D. Vuzman, J. M. L. Martin, J. Phys. Chem. A 112 (2008) 3.

${ }^{86}$ S. Kozuch, D. Gruzman, J. M. L. Martin, J. Phys. Chem. C 114 (2010) 20801.

${ }^{87}$ S. Kozuch, J. M. L. Martin, Phys. Chem. Chem. Phys. 13 (2011) 20104.

${ }^{88}$ S. Kozuch, J. M. L. J. Martin, Comp. Chem. 34 (2013) 2327.

${ }^{89}$ T. Yanai, D. Tew, N. Handy, Chem. Phys. Lett. 393 (2004) 51.

${ }^{90}$ O. A. Vydrov, G. E. Scuseria, J. Chem. Phys. 125 (2006) 34109.

${ }^{91}$ J.-D. Chai, M. Head-Gordon, J. Chem. Phys. 128 (2008) 084106.

92 J.-D. Chai, M. Head-Gordon, Phys. Chem. Chem. Phys. 10 (2008) 6615.

${ }^{93}$ R. Peverati, D. G. Truhlar, J. Phys. Chem. Lett. 2 (2011) 2810.

${ }^{94}$ L. A. Curtiss, P. C. Redfern, K. Raghavachari, J. Chem. Phys. 126 (2007) 084108.

${ }^{95}$ L. A. Curtiss, P. C. Redfern, K. Raghavachari, J. Chem. Phys. 127 (2007) 124105.

${ }^{96}$ B. Chan, J. Deng, L. Radom, J. Chem. Theory Comput. 7 (2011) 112.

${ }^{97}$ J. A. Montgomery Jr, M. J. Frisch, J. W. Ochterski, G. A. Petersson, J. Chem. Phys. 110 (1999) 2822; ibid 112 (2000) 6532.

${ }^{98}$ J. W. Ochterski, G. A. Petersson, J. A. Montgomery Jr, J. Chem. Phys. 104 (1996) 2598.

${ }^{99}$ S. Grimme, J. Chem. Phys. 118 (2003) 9095.

${ }^{100}$ M. Pitonak, P. Neogrady, J. Cerny, S. Grimme, P. Hobza, Chem. Phys. Chem. 10 (2009) 282.

${ }^{101}$ S. Grimme, J. Comput. Chem. 24 (2003) 1529.

${ }^{102}$ T. Takatani, E. E. Hohenstein, C. D. Sherrill, J. Chem. Phys. 128 (2008) 124111.

${ }^{103}$ M. Pitonak, J. Rezac and P. Hobza, Phys. Chem. Chem. Phys. 12 (2011) 9611.

${ }^{104}$ H. Y. Afeefy, J. F. Liebman, S. E. Stein, Neutral Thermochemical Data. In NIST Chemistry WebBook, NIST Standard Reference Database Number 69; Linstrom, P. J., Mallard, W. G., Eds.; National Institute of Standards and Technology: Gaithersburg, MD; see http://webbook.nist.gov (accessed May 20, 2014).

${ }^{105}$ P. Mori-Sanchez, A. J. Cohen and W. Yang, J. Chem. Phys. 125 (2006) 201102.

${ }^{106}$ A. Halkier, T. Helgaker, P. Jørgensen, W. Klopper, H. Koch, J. Olsen and A. K. Wilson, Chem. Phys. Lett. 286 (1998) 243.

${ }^{107}$ D. G. Liakos, F. Neese, J. Phys. Chem. A116 (2012) 4801.

${ }^{108}$ P. Jurečka, P. Hobza, Chem. Phys. Lett. 365 (2002) 89.

${ }^{109}$ W. Klopper, H. P. Lüthi, Mol. Phys. 96 (1999) 559.

${ }^{110}$ J. M. L. Martin, Theor. Chem. Acc. 97 (1997) 227. 


\section{Graphical TOC}

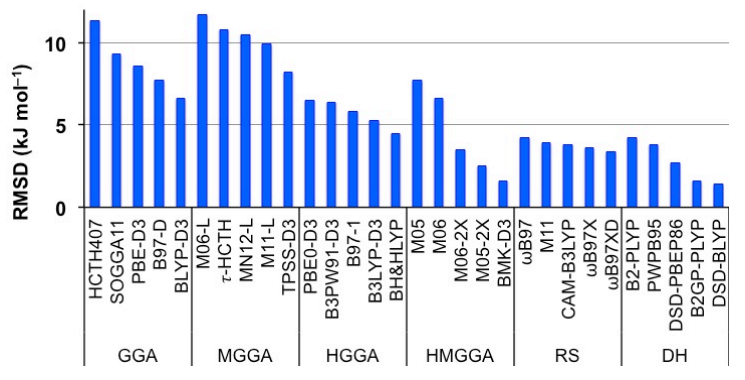

